Article

www.mdpi.com/journal/remotesensing

\title{
Automatic Detection of Buildings and Changes in Buildings for Updating of Maps
}

\author{
Leena Matikainen *, Juha Hyyppä, Eero Ahokas, Lauri Markelin and Harri Kaartinen \\ Department of Remote Sensing and Photogrammetry, Finnish Geodetic Institute, P.O. Box 15, \\ FI-02431 Masala, Finland; E-Mails: Juha.Hyyppa@fgi.fi (J.H.); Eero.Ahokas@fgi.fi (E.A.); \\ Lauri.Markelin@fgi.fi (L.M.); Harri.Kaartinen@fgi.fi (H.K.) \\ * Author to whom correspondence should be addressed; E-Mail: Leena.Matikainen@fgi.fi; \\ Tel.: +358-9-295-55204; Fax: +358-9-295-55200.
}

Received: 24 February 2010; in revised form: 20 April 2010 / Accepted: 21 April 2010 /

Published: 27 April 2010

\begin{abstract}
There is currently high interest in developing automated methods to assist the updating of map databases. This study presents methods for automatic detection of buildings and changes in buildings from airborne laser scanner and digital aerial image data and shows the potential usefulness of the methods with thorough experiments in a $5 \mathrm{~km}^{2}$ suburban study area. $96 \%$ of buildings larger than $60 \mathrm{~m}^{2}$ were correctly detected in the building detection. The completeness and correctness of the change detection for buildings larger than $60 \mathrm{~m}^{2}$ were about $85 \%$ (including five classes). Most of the errors occurred in small or otherwise problematic buildings.
\end{abstract}

Keywords: building; change detection; updating; mapping; automation; laser scanning; aerial image

\section{Introduction}

\subsection{Motivation}

Operational mapping of topographic objects using remote sensing is today still mainly based on visual interpretation and manual digitizing. Updating of map databases requires time-consuming work for human operators to search for changed objects and to digitize the changes. There is thus high interest in mapping organizations in developing automated tools to assist the update process, for example to detect changes in buildings and other object classes automatically (e.g., [1-8]). Up-to-date 
information on buildings is important for map users, and changes in this class are common as new buildings are built and old ones are demolished or changed.

Our study concentrates on the automatic detection of buildings and changes in buildings. The availability of airborne laser scanner (ALS) data and digital aerial images with multispectral channels has clearly improved the possibility of developing useful automated tools for these tasks. When accurate height information from laser scanning is available, buildings can be distinguished from the ground surface, which makes the interpretation task easier and reduces the number of misclassifications. Digital surface models (DSMs) created from aerial images or high-resolution satellite images can also be used, but their quality for classification is typically lower (e.g., [9,10]). Multispectral image data are useful in distinguishing buildings from vegetation, although the use of laser scanner data alone can also be sufficient.

\subsection{Previous Studies}

Different automatic change detection approaches for buildings are possible. If both old and new datasets are available, change detection between the datasets can be carried out. Murakami et al. [11] presented a simple approach based on subtracting one laser scanner derived DSM from another. Vögtle and Steinle's method [12] compared laser DSMs in an object-based manner by analyzing building objects that were first extracted from the DSMs. Other studies using multitemporal laser scanner or image data have been presented, for example, by Jung [13], Vu et al. [14], Butkiewicz et al. [15], and Nakagawa and Shibasaki [16].

Another basic approach for change detection is to detect buildings from new data and compare the results with the existing building map to detect changes. This approach is needed if laser scanner and image data corresponding to the state of the old map are not available. It is also feasible from the point of view of a mapping agency that maintains a topographic database and aims to detect changes between the database and up-to-date image data [8]. Hoffmann et al. [17] studied segment-based detection of buildings from a DSM and multispectral data obtained from digital airborne imagery. Change detection was also discussed briefly. Knudsen and Olsen [4,18] presented a method that was based on pixel-based spectral classification of image data followed by change detection. Further developments of the method include the use of DSM data [19]. In our earlier studies, we used laser scanner [20,21] and aerial image [21] data and a segment-based classification approach to detect buildings. Change detection between the building detection results and a building map was based on analyzing the overlaps of building objects without actual matching of these objects. Vosselman et al. also used laser scanner data [22,23], color imagery [22] and a segment-based classification approach. The change detection was carried out between building objects. To take into account differences between database objects and extracted building objects, the method used morphological operations, shifting of objects and mapping rules. The method developed by Rottensteiner $[9,24]$ used a DSM and multispectral imagery and included pixel-based and region-based classification steps. A topological clarification stage was included to achieve topological consistency between the existing map and building detection results before change detection. Holland et al. [8] tested different classification approaches for digital aerial image data and a DSM created from the images. A change detection approach for detecting demolished and new buildings was also developed. In addition to change 
detection, existing map data have been exploited in these studies to determine training areas $[4,18]$, to give additional support for deciding whether a pixel belongs to a building or not [9,24], and to mask out areas where buildings are not likely to occur [8].

Change detection approaches concentrating on the verification of map data have also been developed. Similar to the methods discussed above, these methods use existing map data and new remotely sensed data, but they use the map data more directly as a starting point, for example, by analyzing building boundaries [7,25]. New buildings are then extracted separately. Recently Bouziani et al. [26] presented a knowledge-based change detection method for the detection of demolished and new buildings from very high resolution satellite images. Different object properties, including possible transitions and contextual relationships between object classes, were taken into account. Map data were used to determine processing parameters and to learn object properties.

For the task of automatic building detection from ALS, or ALS and image data, a large number of different methods have been presented ([22,27-43] and many others). Among these methods, step-wise classification approaches exploiting many different input features are typical. The input features can include, for example, height difference between a DSM and a digital terrain model (DTM) (also called a normalized DSM, nDSM), height difference between first pulse and last pulse laser scanner data, height texture or surface roughness, reflectance information from images or laser scanning, and shape and size of objects. New methods for both building detection and change detection are presented constantly (see, for example, [44]). The newest methods include, for example, the use of full-waveform laser scanner data for classifying urban areas [45]. Compared with conventional laser scanner data, full-waveform data offer new and potentially useful features for classification. Recently, interest has also turned to comparison of different methods and input features [10,46-48].

The previous studies have demonstrated that automatic detection of buildings and changes in buildings is possible and relatively good results can be achieved, although false detections of changes are also typical $[4,10]$. Quality evaluation of the results has received special attention, especially in recent studies (e.g., [10,47,49]). On the other hand, test datasets, especially in change detection studies, have been rather limited in size. Simulated changes rather than real ones have often been used to evaluate the accuracy (e.g., [9,10,24]). A larger production test was carried out by Holland et al. [8], who tested their change detection method for two test sites, covering $23 \mathrm{~km}^{2}$ and $25 \mathrm{~km}^{2}$. Many false detections also occurred in that study, but generally the test results were promising. Overall, however, it seems that research is still needed to develop useful change detection methods. In particular, to be able to develop better methods and evaluate their feasibility for practical use, detailed information is needed on the quality of the results and typical errors.

\subsection{Contribution of Our Study}

Since multitemporal laser scanner and digital aerial image datasets are not yet in common use, our change detection method is based on comparison of an existing building map and building detection results, i.e., it belongs to the second category of approaches discussed above. The idea is that the results could be utilized in further steps of the update process, which could be either manual or automatic. The methods presented in this article are improved versions of those presented in [20,21]. The improved building detection method uses the classification tree method, which is a highly 
automated method and is easier to apply to new input data than the classification rules used in the earlier method. The change detection method is based on matching and comparison of building objects. It includes two alternative methods for detecting changed buildings and some additional rules relying on existing map data in cases where misclassifications are likely. The processes are unique and carefully planned, although similar tools and ideas have also been utilized in some other studies in recent years, as described above and in the Methods Section (see 3.1.1 and 3.2.1). The methods were tested by applying them to laser scanner and digital aerial image data from a suburban study area covering about $5 \mathrm{~km}^{2}$. The quality of the results was thoroughly evaluated by using two real building maps of the area, which provided a large reference dataset with many real changes and was different from previous change detection studies. We expect that such an analysis can increase knowledge on the performance of automated building detection and change detection methods and highlight problems for further development.

\section{Study Area and Data}

\subsection{Study Area}

A suburban study area of Espoonlahti was used in the method development and testing (see Figure 1). The area is located in the city of Espoo on the southern coast of Finland and belongs to the metropolitan region of Helsinki. It contains buildings of different sizes from small houses and sheds to large industrial buildings. The roofs of the buildings have various shapes, colors and material types. High-rise and industrial buildings have usually flat roofs, while saddle roofs are typical of smaller buildings. Typical roof materials include roofing felt, tiles and roofing sheet. The topography of the area is varied, and there are many small hills (the altitude varies between $0 \mathrm{~m}$ and $55 \mathrm{~m}$ above sea level). There is also plenty of coniferous and deciduous vegetation in the area, which is partly covered by forest. The most common tree species are spruce, pine and birch, but there are also many other species, especially in built-up areas.

The study area was divided into a training area of about $0.8 \mathrm{~km}^{2}$ and five test areas covering about $4.5 \mathrm{~km}^{2}$ in total. The test areas represent four different types of suburban area: high-rise, low-rise, industrial areas, and a new residential area with both high-rise and low-rise buildings. This definition, however, is not strict. For example, some low-rise buildings occur in the high-rise areas and vice versa. The training area was defined so that it includes many different types of buildings and land cover. The five test areas were processed separately. If a building was located on the boundary between the areas, it was treated as two (or more) separate buildings.

\subsection{Data}

ALS data, an aerial color ortho image mosaic and two building maps were used in the study. All these data were processed into raster format with a pixel size of $30 \mathrm{~cm} \times 30 \mathrm{~cm}$ in the Finnish ETRS-TM35FIN coordinate system (ETRS is European Terrestrial Reference System, and TM is Transverse Mercator). 
Figure 1. Minimum DSM from different subareas of the study area. The training area was used for creating classification rules and the other areas were used for testing the methods.
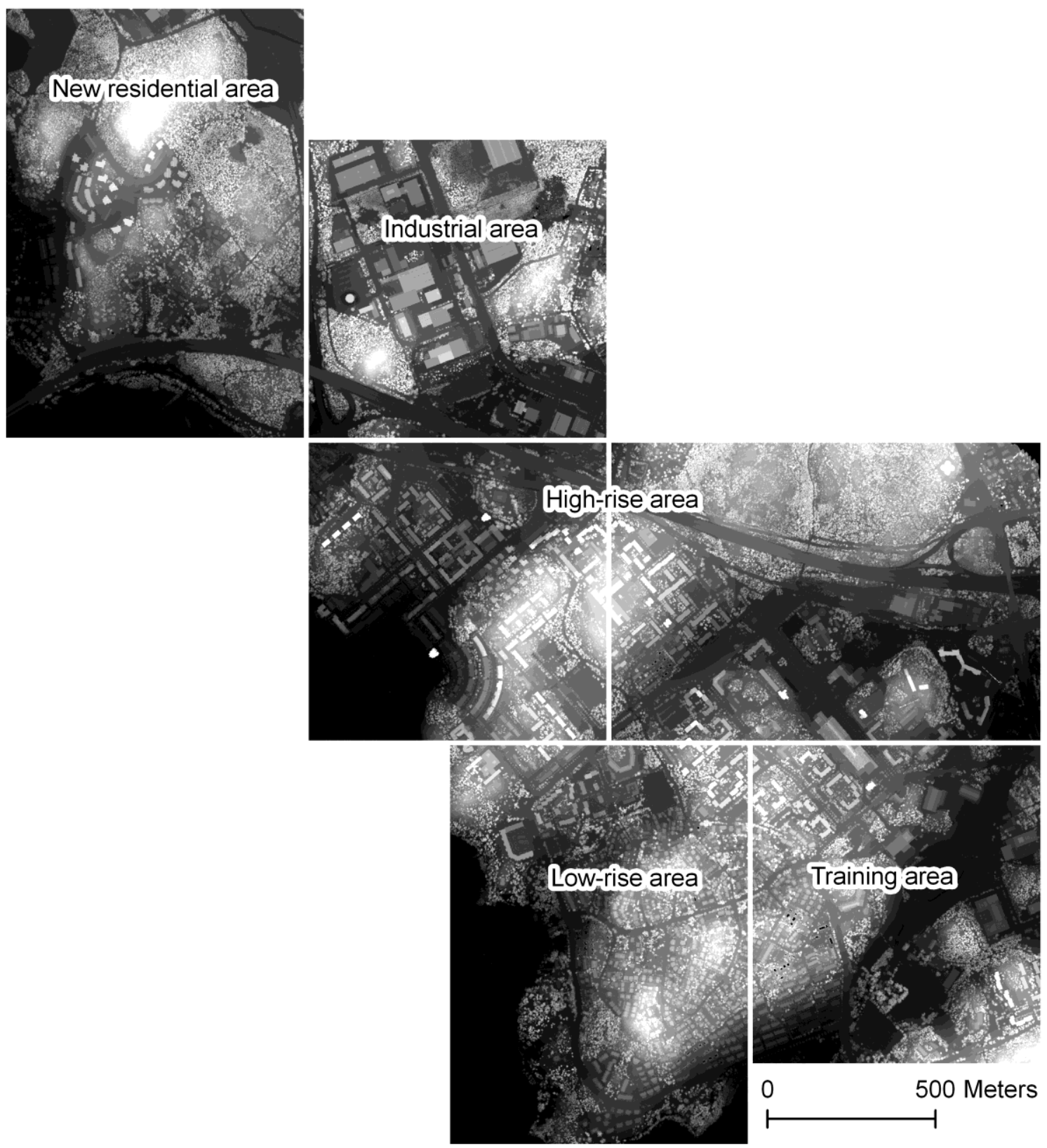

\subsubsection{Laser Scanner Data}

The laser scanner data were acquired on 12 July 2005 with the Optech Airborne Laser Terrain Mapper (ALTM) 3100 laser scanner from a flying altitude of about 1,000 $\mathrm{m}$. The point density in areas covered by single strips is about 2-4 points $/ \mathrm{m}^{2}$. The classification routines of the TerraScan software [50] were used to classify the laser points into ground points and points clearly above ground (threshold value $2.5 \mathrm{~m}$ ). The ground classification routine is based on a filtering algorithm developed by Axelsson [51]. Two raster DSMs (maximum and minimum DSMs) were created in TerraScan by selecting the highest or lowest height for each pixel and interpolating the values for pixels without laser points. First and last pulse points were not separated, but the maximum and minimum DSMs should approximately correspond to a first pulse and last pulse DSM, respectively. Many buildings 
were generally missing from the laser data, i.e., there were only few reflections from the roofs of these buildings, and there were thus gaps in the laser data. Typically, these gaps were caused by low-rise buildings with dark saddle roofs. The missing buildings were excluded from the training data by using a manually defined mask. In the test areas, masks were defined automatically and they included empty pixels in the interpolated DSMs. Pixels under the mask were excluded from building detection. Map buildings containing any pixels under the mask were also excluded from change detection.

\subsubsection{Aerial Image Data}

The ortho image mosaic with red, green, blue and near-infrared channels was created from digital aerial images acquired with the Intergraph Digital Mapping Camera (DMC) on 1 September 2005. The flying altitude was $500 \mathrm{~m}$. Image Station Base Rectifier (ISBR) [52] and ERDAS IMAGINE [53] software were used to create the ortho images and the mosaic. A laser scanner derived DSM was used in the rectification, which ensures that roofs of the buildings are approximately correctly located. Areas behind buildings or trees in the original image data, however, could not be corrected, and there are thus some distortions in the shapes of the buildings, especially for the highest buildings. This did not cause major problems in the study, because the geometry of the detected objects was determined on the basis of segmentation of the laser scanner derived minimum DSM. There are also some brightness variations in the digital numbers ( $\mathrm{DN}$ ) of the ortho mosaic because no radiometric corrections were applied to the data during the image postprocessing and mosaicking. The difference in the acquisition time between the laser and image data was about 1.5 months, and small differences thus occur in the datasets, for example in a few buildings under construction. Considering the entire study area, however, the effect of this is likely to be negligible. Trees were in full leaf in both datasets.

\subsubsection{Map Data}

Building vectors of the Topographic Database from 2000, produced by the National Land Survey of Finland (NLSF), were used to create an old map to be updated (this was not the newest version of the database but was used to obtain realistic circumstances for the study). The Topographic Database contains the basic topographic data covering the entire country of Finland. The required positional accuracy for buildings in the database is $3 \mathrm{~m} \mathrm{[54].}$

An up-to-date map used as reference data was created from building vectors of a city base map obtained from the city of Espoo. The map data originally represented the situation in 2008 but were modified, to represent the situation in 2005 , by removing the newest buildings and adding some demolished buildings from an older version of the map. Buildings smaller than $20 \mathrm{~m}^{2}$ were also removed, because they were not considered in the study. The city base map is a large-scale and detailed topographic map used, for example, for city planning. In printed form, it is available on scales between 1:1,000 and 1:4,000. The map presents the buildings in more detail and generally has higher accuracy than the Topographic Database. It also includes more small buildings. In an earlier study we estimated the positional accuracy of buildings to be $0.5 \mathrm{~m}$ or better. Coordinate transformation and processing into raster format may have added some uncertainty to both maps. It is also very important to note that buildings appear different on the maps and in remotely sensed data. An obvious difference, in addition to generalization, is that the maps represent the bases of the buildings instead of roof edges. 
A $100 \%$ correspondence between building detection results and map data would thus not be reached in a pixel-based comparison even if the detection process worked perfectly. On the other hand, the use of real maps provides realistic information on the performance of automated methods compared with current map data.

\section{Methods}

\subsection{Building Detection}

\subsubsection{Building Detection Method}

The main idea of the building detection method is to firstly segment a laser scanner derived DSM into homogeneous regions using the height information and then to classify the segments on the basis of their properties in the laser scanner and aerial image data. The first classification step is conducted to distinguish high objects, i.e., buildings and trees, from the ground surface. The remaining task is then to distinguish building segments from tree segments. Finally, neighboring building segments are merged to obtain one segment for each building. Postprocessing of the classification results is possible, for example by eliminating small regions classified as buildings. A large majority of non-building high objects in our study area are trees, and we thus prefer to use the class name "tree", but for the purpose of building detection, other high objects, such as poles, are also ideally included in the tree class. Similarly, all low areas are assigned to the ground class, even if there are objects, such as cars or low vegetation, in the data.

For segmentation and calculation of the attributes of the segments we have used the Definiens Professional software [55-57]. The segmentation method is based on bottom-up region merging [58]. Other steps of the building detection method were implemented in Matlab [59]. The classification of the segments into high objects and ground is based on the preclassified laser points (see Section 2.2.1). For each pixel, the highest or lowest point is considered, depending on the DSM used. If most of the points within a segment have a height value clearly above ground ( $2.5 \mathrm{~m}$ in this study), the segment is classified as a high object, and otherwise it is classified as ground. Alternatively, the height difference between the DSM and a DTM for the segments could be used. Some more details of the segmentation and first classification step can be found in [60].

Buildings and trees are distinguished from each other by using the classification tree method [61], which has many useful properties for the analysis of remotely sensed data (see, for example, [62-64]). Classification trees (also called decision trees) can be created automatically with data mining or statistical software tools from a large number of input attributes. The method is non-parametric and does not require assumptions on the distribution of the data. It is thus easy to adapt for new datasets, and the classification process is highly automated. In the context of ALS and aerial image data analysis, classification trees have been used, for example, by Hodgson et al. [65] for mapping of urban parcel imperviousness, Ducic et al. [66] to classify full-waveform laser data, and Jung [13], Matikainen [67], Zingaretti et al. [68], Holland et al. [8] and Im et al. [69] to classify buildings and other classes. The classification tree tools available in the Statistics Toolbox of Matlab were used to implement the classification. 
In the classification tree method, the most useful attributes and splits for the tree are selected automatically by using training data and a splitting criterion. In our method, training segments for buildings and trees are defined on the basis of map data. As the splitting criterion, we have used Gini's diversity index, which is a measure of node impurity and is defined as [61]:

$$
\operatorname{impurity}(t)=\sum_{i \neq j} p(i \mid t) p(j \mid t),
$$

where $t$ is a node, and $p(i \mid t)$ is the proportion of cases $\boldsymbol{x}_{n} \in t$ which belong to class $i$ ( $\boldsymbol{x}$ is a measurement vector, i.e., a vector of attributes for a training segment). At each node of the tree, a search is made for the split that reduces node impurity the most. A node has to contain at least 10 training segments to be split (the default value). The original classification tree is normally large and can overfit the training data. Pruning is thus needed to obtain a set of smaller subtrees. Training data and 10-fold cross-validation are used to estimate the best level of pruning by computing the costs of the subtrees. The costs are based on misclassifications produced by the trees. The best level of pruning is the level that produces the smallest tree within one standard error of the minimum-cost subtree. For further details of the method, see [61,70].

\subsubsection{Building Detection Experiments}

In the building detection experiments of this study, the minimum DSM was segmented and high objects were distinguished. Training segments for buildings and trees were defined automatically by using the up-to-date building map of the training area. If over $80 \%$ of a high segment was covered with buildings on the map, the segment was selected as a training segment for buildings. If over $80 \%$ was empty, i.e., not covered with buildings, the segment was selected as a training segment for trees (the percentage threshold was selected heuristically, which also applies to other threshold values if not mentioned otherwise). The number of tree segments obtained in this way was much larger than the number of building segments. To obtain approximately equal numbers for both classes, only every 12th tree segment was selected. Visual checking of the training segments was also carried out, and some segments were discarded. The final number of training segments was 1,057 for buildings and 1,099 for trees.

Altogether 47 attributes were determined for the training segments (see Table 1). In addition to the DSMs and image channels, the difference between the two DSMs and a morphologically filtered slope image calculated from the minimum DSM were used as input data for calculating the attributes. The attributes were given as input data for the classification tree method, which created a classification tree automatically. The script created for the construction of the tree was run five times to find the best level of pruning. The estimated level may vary slightly between the runs because the subsamples for cross-validation are selected randomly. Two different levels were suggested in these runs. The tree with the nodes shown in Figure 2 was selected because it led to a slightly more complete detection of buildings in the training area (pixel-based completeness 0.5 percentage units higher, correctness 0.5 percentage units lower). Attributes in this tree included the Normalized Difference Vegetation Index (NDVI), mean slope, Grey Level Co-occurrence Matrix (GLCM) homogeneity calculated from the maximum DSM, and GLCM homogeneity calculated from the near-infrared channel of the aerial image. 
Table 1. Attributes used in the construction of the classification tree. The attributes, except the plane fitting mean squared error (MSE), were obtained from the Definiens software. The Grey Level Co-occurrence Matrix (GLCM) homogeneity is a texture measure originally presented by Haralick et al. [71].

\begin{tabular}{ll}
\hline Data source & Attributes for segments \\
\hline Minimum DSM & $\begin{array}{l}\text { Standard deviation, GLCM homogeneity, MSE obtained when } \\
\text { fitting a plane to the height values }\end{array}$ \\
\hline Maximum DSM & Standard deviation, GLCM homogeneity \\
\hline DSM difference & Mean, standard deviation \\
\hline Slope image & Mean \\
\hline Aerial image & $\begin{array}{l}\text { Separately for all channels: mean, standard deviation, GLCM } \\
\text { homogeneity }\end{array}$ \\
\hline Segments and & $\begin{array}{l}\text { Normalized Difference Vegetation Index (NDVI) calculated from } \\
\text { the mean values in the red and near-infrared channels }\end{array}$ \\
polygons $\quad$ shape & $\begin{array}{l}\text { 26 shape attributes [56]: *) area, area excluding inner polygons (p.), area } \\
\text { including inner polygons (p.), asymmetry, average length of edges (p.), border }\end{array}$ \\
drom the segments & $\begin{array}{l}\text { index, border length, compactness, compactness (p.), density, edges longer than } \\
\text { of edges (p.), number of inner objects (p.), number of right angles with edges } \\
\text { longer than 20 pixels (p.), perimeter (p.), radius of largest enclosed ellipse, radius } \\
\text { of smallest enclosing ellipse, rectangular fit, roundness, shape index, standard } \\
\text { deviation of length of edges (p.), width }\end{array}$ \\
\hline
\end{tabular}

*) Polygon-based attributes were marked with “(p.)". Parameter values for shape polygons and edge length were selected by testing different alternatives and comparing attribute histograms of the training segments.

The mean slope and GLCM homogeneity calculated from a DSM were also selected in classification trees automatically in our previous study with a different dataset [72]. They thus seem to be useful attributes for distinguishing buildings from trees. The near-infrared channel and NDVI were not available in the previous study, but they are obviously useful, especially when there are leaves in deciduous trees. The classification of the dataset used in the present study was also tested by excluding attributes calculated from the aerial image data, but the quality of the results was lower (pixel-based completeness and correctness 0.6 and 4.4 percentage units lower, respectively) [73].

The selected tree was applied to classification of the test areas. In postprocessing of the building detection results, two slightly different algorithms were tested for each area. The first one removed buildings smaller than $20 \mathrm{~m}^{2}$. The second one also removed buildings smaller than $30 \mathrm{~m}^{2}$ if they had a solidity value lower than 0.8 (the solidity is a shape attribute from Matlab, representing the ratio between the area of the region and the area of the smallest convex polygon that can contain the region). After visual and numerical quality evaluations, the results of the first approach were selected for the low-rise area and the results of the second approach for other areas (differences in pixel-based completeness and correctness between the methods were less than 1 percentage unit in each area). 
Figure 2. Classification tree used in the building detection tests. GLCM hom. of max. DSM is GLCM homogeneity calculated from the maximum DSM, and GLCM hom. of NIR ch. is GLCM homogeneity calculated from the near-infrared channel of the aerial image.

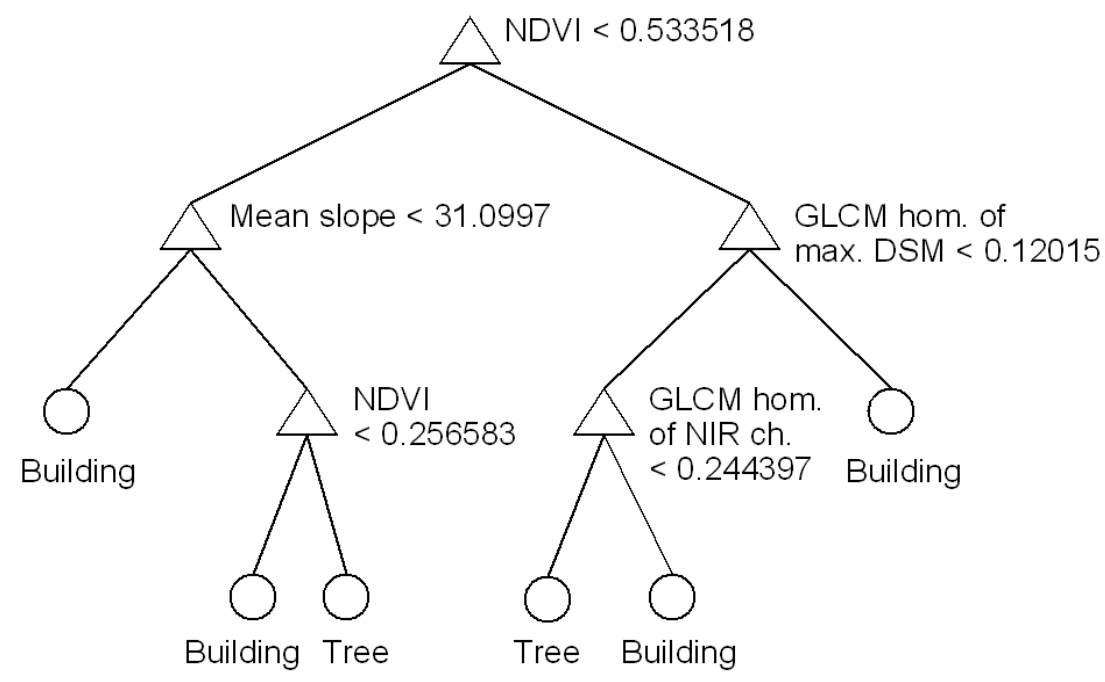

\subsection{Change Detection}

\subsubsection{Change Detection Method}

The change detection method is based on comparison of the existing building map with the building detection results. The method was implemented in Matlab. It uses input data in raster format, but it is object-based, i.e., individual building objects are analyzed. Before comparison, buildings in the two datasets are matched to each other. Matching and comparison of map objects are topics that have wide use in the field of geographical information system (GIS) data processing and updating, and many studies related to the topic can be found in the literature (e.g., [74-76]). In our case, relatively simple methods, capable of using the building detection results as a basis for change detection, were developed. The methods use overlap analysis and buffers created around the objects by using morphological operations. Similar tools have also been utilized in some other change detection studies $[3,9,22]$.

It was assumed that the positional accuracy of the map and remotely sensed data is so good that matching and comparison of building objects can be based on their overlap. Small differences in the location and appearance of the buildings are allowed by the change detection rules. Larger differences are considered as changes or errors that need further attention in the update process. It was also assumed that buildings are detached objects because this is normally the case in Finland. If there are blocks of buildings connected to each other, these are treated as one building object.

If there is any overlap between a pair of buildings on the map and in the building detection results, these are considered as corresponding buildings. Change detection is based on these correspondences (for examples of the different cases, see Figure 3):

- One building on the map corresponds to one in the building detection (1-1). This is an unchanged (OK, class 1) or changed building (class 2). 
- No buildings on the map, one in the building detection (0-1). This is a new building (class 3).

- One building on the map, no buildings in the building detection (1-0). This is possibly a demolished building (class 4).

- One building on the map, more than one in the building detection (1-n), or vice versa (n-1). This can be a real change (e.g., one building demolished, several new buildings constructed), or it can be related to generalization or inaccuracy of the map or problems in building detection. These buildings are assigned to class $5: 1-n / n-1$.

Figure 3. Examples of different change classes. The minimum DSM and old building map are presented on the left, the building detection result in the middle and the change detection result on the right (overlap approach used). (a) Unchanged buildings, changed buildings and a 1-n building. (b) New buildings, changed buildings and an unchanged building. (c) A demolished building and an unchanged building. (d) An n-1 building. (e) Buildings under trees (tree cover examined), unchanged buildings and new buildings. (f) A low car park (DSM examined) and an unchanged building. New and changed buildings for the change detection results were taken from building detection, others from the old map. Buildings of the old map (c) The National Land Survey of Finland 2001, permission number MML/VIR/MYY/219/09.
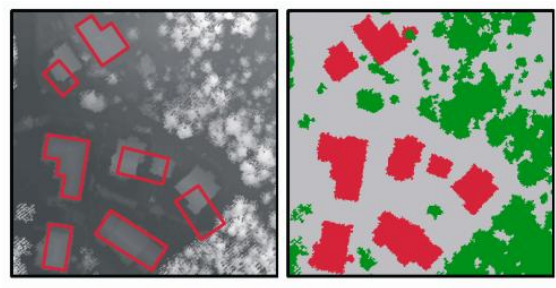

(a)
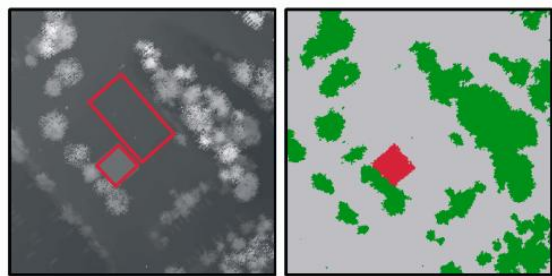

(c)
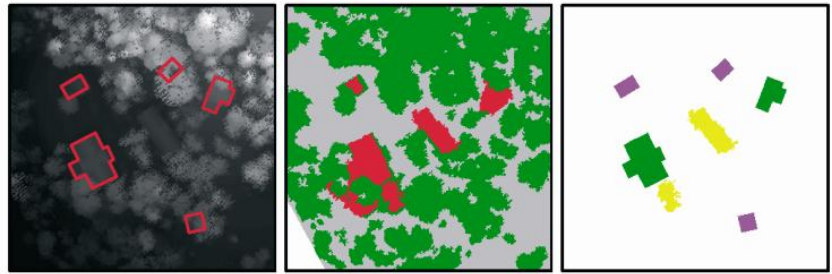

(e)

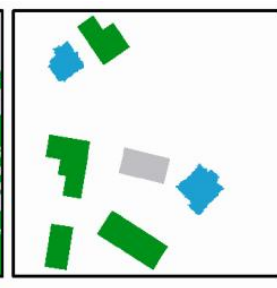

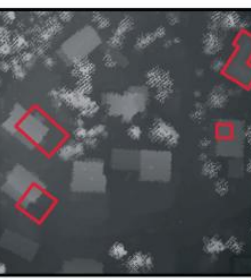

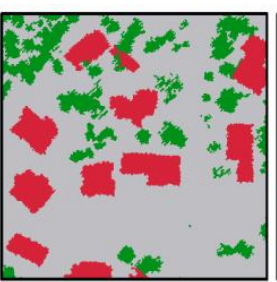

(b)
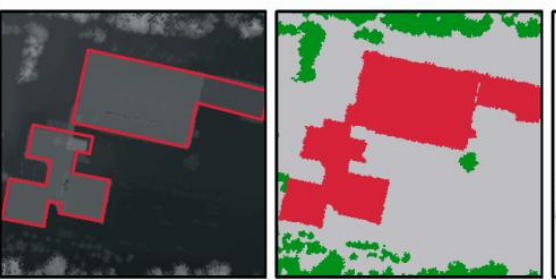

(d)
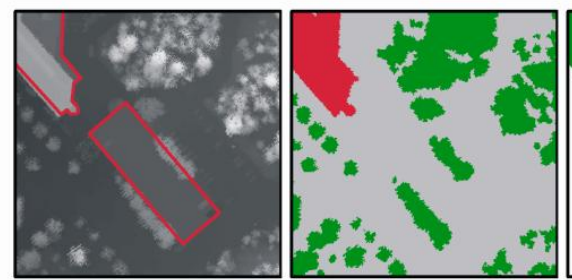

(f)
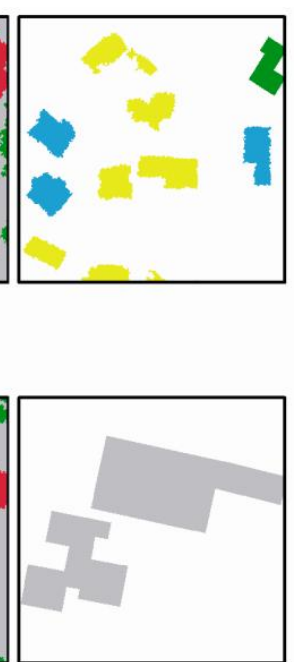

Legend for the change detection results

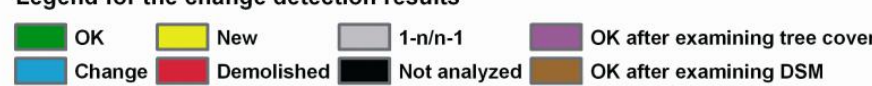

Change Demolished Not analyzed OK after examining DSM

Legend for the building detection results

$\square$ Building $\square$ Tree $\square$ Ground $\square$ Outside study area

Map buildings and new buildings smaller than a threshold value $\left(20 \mathrm{~m}^{2}\right.$ in this study) and buildings including outside pixels (e.g., missing data) are excluded from the analysis and assigned to class 6: not 
analyzed. For the detection of changed buildings (class 2), two different alternatives are possible: overlap percentages or a buffer approach. The user can select which of these is used and determine threshold values. If the overlap approach is used, the percentage of overlapping area is considered both for the building on the map and the detected building. Both of these percentages must be at a required level to label the building as unchanged, i.e.,

$$
\begin{aligned}
& 100 * \frac{A_{\text {overlap }}}{A_{\text {map_building }}} \geq T h r, \text { and } \\
& 100 * \frac{A_{\text {overlap }}}{A_{\text {detected_building }}} \geq T h r,
\end{aligned}
$$

where $A$ is area and $T h r$ is a threshold value.

If the buffer approach is used, a buffer is created around the boundary of the building on the map by using the morphological operations dilation and erosion. The building is considered unchanged if the inner part of the building is detected as a building and the detected building does not extend outside the buffer area (Figure 4). Some misclassifications can be allowed for by using percentage thresholds. If the buffer covers the building completely, it is assigned to class 6 .

There are some typical errors from the building detection step that also cause false changes to be detected in the change detection stage. These include:

1. Missing buildings or building parts due to tree cover (demolished or changed buildings in change detection).

2. Missing buildings or building parts due to their low height (demolished or changed buildings).

3. Enlarged buildings due to their connection with nearby vegetation (changed buildings).

4. Misclassification of other objects as buildings (new buildings).

Figure 4. Illustration of the buffer approach to detect changed buildings. (a) The basic principle. The black line represents a building on the old map. To consider the building unchanged, the inner part of the building (the red area) should be detected as a building and the detected building should not extend outside the buffer (to the gray area). (b) An unchanged building. The red line represents the detected building. (c) and (d) Changed buildings.

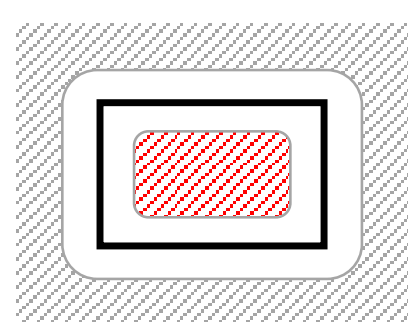

(a)

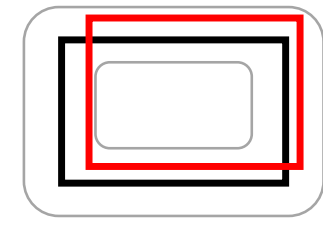

(b)

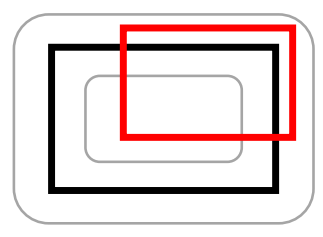

(c)

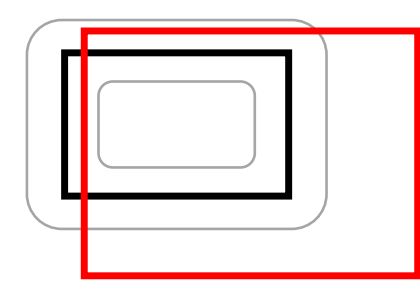

(d)

Special correction rules were developed to take into account the first two cases (the second one only for entire buildings). The objective of these rules is to rely on the map data when it is known that misclassifications are likely. The rules are used to investigate tree cover and DSM in the case of 
buildings that seem to be demolished and tree cover in the case of buildings that seem to have changed so that they are smaller in the building detection results than on the map. Firstly, there is a test to see whether over $90 \%$ of a demolished building or the missing area of a changed building has been classified as tree. In this case, it is likely that tree cover has prevented proper detection of the building. Misclassification of the building as tree is also possible. A demolition or change is less likely, assuming that the majority of buildings will be unchanged and that the most likely class for an area of a recently demolished building is ground. These buildings are assigned to class 7: assumed to be OK after examining tree cover. If the tree cover condition is not satisfied for a demolished building, the DSM is examined by comparing the mean height of the building on the map with the height of the surrounding pixels (located 3.6-3.9 $\mathrm{m}$ from the boundary in this study; the distance was determined by taking into account the positional accuracy of the map, the fact that buildings are typically larger in the DSM than on the map, and visual evaluation). To exclude trees, only pixels classified as ground are considered. If the height difference is over $1.5 \mathrm{~m}$ for at least $25 \%$ of the surrounding pixels, this is considered as an indication of a building and the building is assigned to class 8: assumed to be OK after examining DSM. This rule can detect buildings lower than $2.5 \mathrm{~m}$, which was used as a threshold value in the original building detection. It can also detect car parks or other buildings that are located on a hill slope and have part of the roof on or near ground level. The third problem listed above could be approached, for example, by further analysis of aerial image data for the detected buildings. The ortho image mosaic used in this study, however, was not suitable for the task due to the distortions in the shapes of the buildings (see Section 2.2.2). Effects of the fourth problem can be diminished by analyzing the shape and size of the detected buildings. In this study, this was carried out in the postprocessing step of building detection by eliminating very small buildings.

The buildings on the map and in the building detection results are labeled separately but in such a way that the labels are consistent. For example, a building classified as changed is assigned to class 2 both on the map and in the building detection results. Different presentations can be created from the change detection results. For example, new and changed buildings can be taken from the building detection results, others from the map. The results are also provided as text files that can be imported as attributes to vector maps, i.e., the existing building map or the building detection results converted into vectors. The extraction and correction of boundaries of changed buildings, as well as actual updating of the database, remain tasks to be completed in later stages of the update process. Depending on the objectives and accuracy requirements of the updating, attention should be paid to classes $2-8$ or part of them.

\subsubsection{Change Detection Experiments}

Two different change detection scenarios were tested in this study. In the first test, the objective was only to detect significant changes. The overlap approach was used, and the required overlap to consider a building unchanged was set to $50 \%$. In the second test, the objective was to also detect more subtle changes in the appearance of the buildings, and the buffer approach was selected. The positional accuracy and other characteristics of the old building map were taken into account to select the buffer width, which was set to $2.1 \mathrm{~m}$ (inside building boundary) $+3.6 \mathrm{~m}$ (outside). The number of misclassifications allowed inside and outside the building was $5 \%$, calculated separately for both cases 
as a percentage of the area of the inner part. The tree cover and DSM correction rules were used in both tests.

\subsection{Accuracy Estimation}

\subsubsection{Accuracy Estimation of Building Detection Results}

The accuracy of the building detection results was estimated by using pixel-based and buildingbased accuracy measures. To obtain a good understanding of the quality of the results, the use of different measures is important (e.g., [49,77,78]). In the pixel-based estimation, the results were compared pixel by pixel with the reference map and completeness (i.e., producer's accuracy or interpretation accuracy), correctness (i.e., user's accuracy or object accuracy) and mean accuracy were calculated for buildings [79,80]. The equation for mean accuracy [79] is:

$$
\text { Mean accuracy }=\frac{2 n_{C B} \& M B}{n_{M B}+n_{C B}} 100 \%,
$$

where $n_{C B} \& M B$ is the number of pixels labeled as buildings both in the building detection results and on the map, $n_{M B}$ is the total number of pixels labeled as buildings on the map, and $n_{C B}$ is the total number of pixels labeled as buildings in the building detection results.

In the building-based estimation, a building on the map was considered correctly detected if a certain percentage of its area (determined by a threshold value) was labeled as building in the building detection results. Map buildings containing missing laser data were excluded by using the masks (see Section 2.2.1). Similarly, a building in the building detection results was considered a correct building if a certain percentage of it was labeled as building on the map. All detected buildings were considered. Matching of building objects was not carried out. The estimation was run with two different threshold values: $50 \%$ and 1\%. Rutzinger et al. [49] suggested that a threshold value between $50 \%$ and $70 \%$ should be selected for this type of evaluation. Song and Haithcoat [77], on the other hand, accepted any overlap to consider a building correct. We assume that small threshold values can also be useful if the buildings are detached objects and the objective is to measure the performance of the method in detecting buildings, regardless of the quality of their shape. For example, from sparse laser scanner data it can be possible to detect the majority of the buildings, at least partly [81]. This might provide useful information for a human operator in the update process, even if the shape of all detected buildings is not good. Similar to Zhan et al. [78], Rottensteiner et al. [47], Champion et al. [10] and Rutzinger et al. [49], curves showing the accuracy estimates as a function of building size were created.

\subsubsection{Accuracy Estimation of Change Detection Results}

For evaluating the change detection results, reference results were created by carrying out change detection between the old and new building maps. The method and parameter settings were the same as those used for the actual change detection, but naturally, the tree cover and DSM correction rules were not applied. A confusion matrix was created, and completeness and correctness were estimated separately for different classes and buildings of different sizes. This accuracy estimation was 
building-based. Comparison of the results, except for new buildings, was based on comparing labels given for the buildings on the old map. Comparison of new buildings was based on their overlap. If there was any overlap between a new building in the change detection results and new buildings in the reference results, the building was considered correct. Two sets of accuracy estimates were calculated. In the first case, classes 1-5 were considered. In the second case, class 5 was excluded. Classes 7 and 8 were included in class 1 in both cases. There are many reasons for classifying a building as class 5 (see the description of the change detection method in Section 3.2.1), and errors are not always related to building detection. The true accuracy is thus likely to lie somewhere between the two estimates. Curves showing the accuracy estimates as a function of building size (buildings $\geq$ threshold value) were created.

\section{Results and Discussion}

\subsection{Building Detection Results}

Building detection results for the test areas are presented in Figure 5. More detailed results for some buildings can be seen in Figure 3. Table 2 shows the pixel-based accuracy estimates for the building detection results. The building-based estimates for buildings of different sizes are presented in Figure 6. A summary of these estimates is also presented in Table 3.

According to the pixel-based estimates, the mean accuracy of buildings was $89 \%$. The accuracy was lowest $(83 \%)$ in the new residential area. It could be expected that new buildings are clearly visible and thus easy to detect, but there are some understandable reasons for the lower accuracy, such as buildings or building parts missing from the map, low car parks and buildings under construction. The highest accuracy (94\%) was achieved in the industrial area, which is natural due to the large building size. As noted by Rutzinger et al. [49], differences between the detected and reference buildings with regards to the building outlines can decrease the pixel-based estimates considerably. In our study, there were remarkable differences in the appearances of the buildings. If the building detection results were compared with a reference map manually delineated from the laser DSM, the accuracy estimates would probably be higher.

Table 2. Pixel-based accuracy estimates for the building detection results.

\begin{tabular}{|c|c|c|c|c|c|}
\hline & $\begin{array}{l}\text { Low-rise } \\
\text { area }\end{array}$ & $\begin{array}{l}\text { High-rise } \\
\text { area }\end{array}$ & $\begin{array}{l}\text { New residential } \\
\text { area }\end{array}$ & $\begin{array}{l}\text { Industrial } \\
\text { area }\end{array}$ & $\begin{array}{l}\text { All } \\
\text { areas }\end{array}$ \\
\hline Completeness & $89.7 \%$ & $90.0 \%$ & $89.2 \%$ & $96.9 \%$ & $91.3 \%$ \\
\hline Correctness & $83.8 \%$ & $89.3 \%$ & $77.7 \%$ & $90.6 \%$ & $87.1 \%$ \\
\hline Mean accuracy & $86.6 \%$ & $89.6 \%$ & $83.1 \%$ & $93.7 \%$ & $89.1 \%$ \\
\hline $\begin{array}{l}\text { Buildings classified } \\
\text { as trees }\end{array}$ & $3.9 \%$ & $2.5 \%$ & $2.5 \%$ & $0.8 \%$ & $2.5 \%$ \\
\hline $\begin{array}{l}\text { Buildings classified } \\
\text { as ground }\end{array}$ & $6.4 \%$ & $7.5 \%$ & $8.3 \%$ & $2.3 \%$ & $6.2 \%$ \\
\hline
\end{tabular}


Figure 5. Building detection results for the test areas.

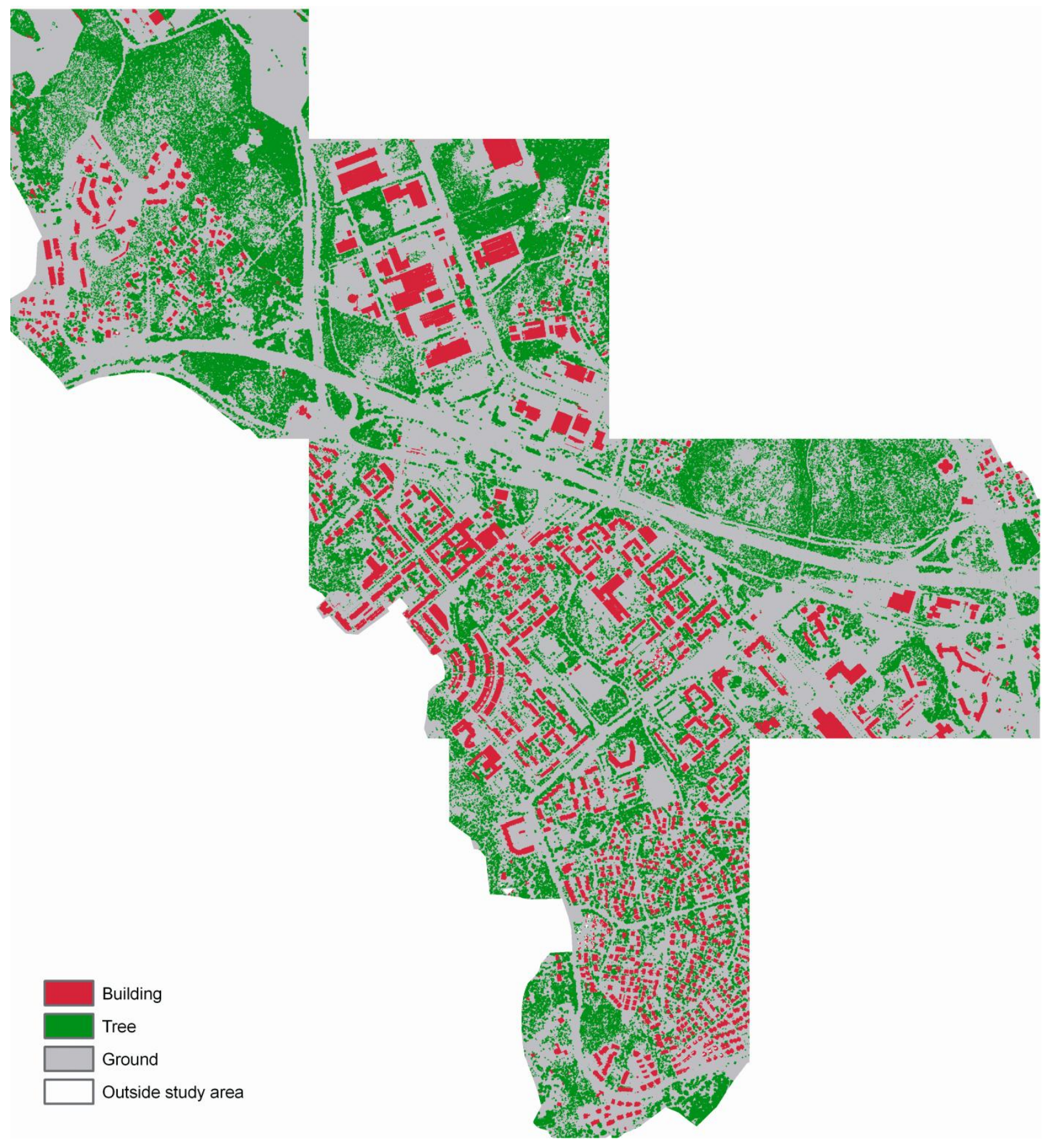


Figure 6. Building-based accuracy estimates for the building detection results as a function of building size. (a) Estimates for all buildings larger than the $\mathrm{X}$ axis value. (b) Estimates for buildings in the size range given by the $\mathrm{X}$ axis values. An overlap of either $50 \%$ or $1 \%$ between reference and detected buildings was required to consider a building correctly detected.

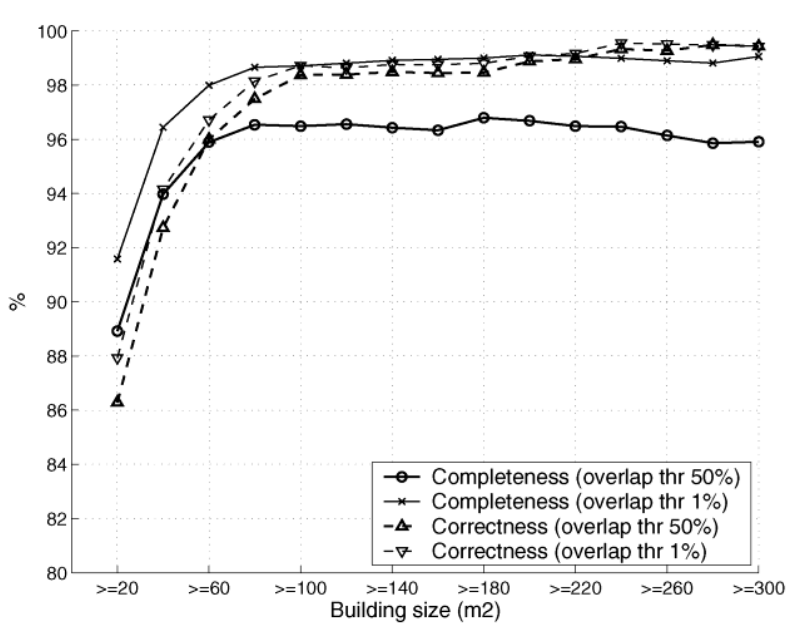

(a)

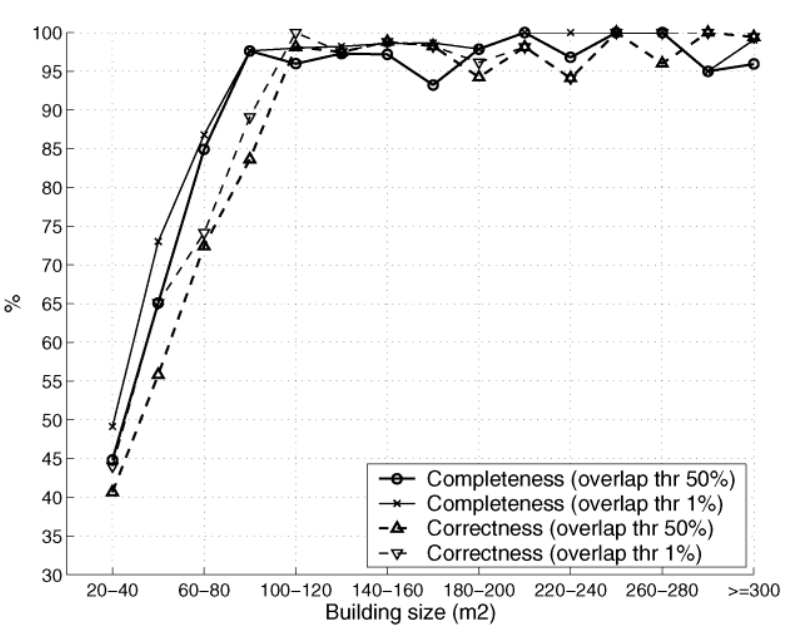

(b)

Table 3. Building-based accuracy estimates for the building detection results. All test areas included. An overlap of either $50 \%$ or $1 \%$ between reference and detected buildings was required to consider a building correctly detected.

\begin{tabular}{ccccc}
\hline $\begin{array}{l}\text { Building size } \\
\left(\mathbf{m}^{2}\right)\end{array}$ & $\begin{array}{l}\text { Number of } \\
\text { buildings in the } \\
\text { reference map }\end{array}$ & $\begin{array}{l}\text { Completeness } \\
\text { (overlap } \\
\text { requirement } \\
\mathbf{5 0 \% / 1 \% )}\end{array}$ & $\begin{array}{l}\text { Number of } \\
\text { buildings in the } \\
\text { building } \\
\text { detection results }\end{array}$ & $\begin{array}{l}\text { Correctness } \\
\text { (overlap } \\
\text { requirement } \\
\mathbf{5 0 \% / 1 \% )}\end{array}$ \\
\hline$\geq 20$ & 1,128 & $88.9 \% / 91.6 \%$ & 1,210 & $86.3 \% / 87.9 \%$ \\
\hline$\geq 40$ & 1,012 & $94.0 \% / 96.4 \%$ & 1,060 & $92.7 \% / 94.2 \%$ \\
\hline$\geq 60$ & 949 & $95.9 \% / 98.0 \%$ & 974 & $96.0 \% / 96.7 \%$ \\
\hline$\geq 80$ & 896 & $96.5 \% / 98.7 \%$ & 916 & $97.5 \% / 98.1 \%$ \\
\hline$\geq 100$ & 854 & $96.5 \% / 98.7 \%$ & 861 & $98.4 \% / 98.7 \%$ \\
\hline$\geq 200$ & 452 & $96.7 \% / 99.1 \%$ & 534 & $98.9 \% / 99.1 \%$ \\
\hline 300 & 318 & $95.9 \% / 99.1 \%$ & 355 & $99.4 \% / 99.4 \%$ \\
\hline
\end{tabular}

The building-based estimates are more tolerant of differences between the map and remotely sensed data, as well as of errors in the shape of the detected buildings. They provide information on the percentage of buildings that were detected (completeness) or correct (correctness), at least partly. For all buildings, the building-based completeness and correctness were $89 \%$ and $86 \%$, respectively, estimated with the overlap requirement of $50 \%$. The estimates rose rapidly with the size of the buildings, and for buildings larger than $60 \mathrm{~m}^{2}$ they were $96 \%$. Some errors also occurred in the largest buildings, but these were special cases. For example, there are several two-level car parks in the area that are located on a hill slope and have the upper level on or near ground level on one side. Many of the car parks were presented with lines forming closed polygons on the original reference map and 
were thus included in the raster map, but not all of them were. Many errors in the building detection occurred for the car parks because they are difficult to distinguish from the ground. A few large buildings in the high-rise area had roofs covered with vegetation and were thus misclassified as trees. Such buildings did not exist in the training data. Two large sheds in the industrial area were not presented on the map, which decreased the correctness slightly. Many of the smallest buildings on the map (typically sheds) were very low and/or covered with trees and thus difficult to detect. For smaller buildings, some discrepancies between the map and laser and image data also occurred. In the industrial area, for example, there were many sheds, containers or other constructions that were detected as buildings but were not presented on the map. Distinguishing such objects from real small buildings is difficult. It also seems that some buses were misclassified as buildings. This might be improved by more detailed classification of different objects (e.g., roads). Some misclassifications occurred between buildings and vegetation. The acquisition date of the laser scanner data was not ideal for building detection because trees were in full leaf.

The pixel-based accuracies of about $90 \%$ are in agreement with our previous studies with earlier versions of the method and different datasets. Values of a similar level have also been reported by other authors (e.g., [47,49]). Comparison of the building-based estimates to other studies, even to our own, is difficult because different evaluation methods and/or threshold values and study areas have been used. Generally, the characteristics of the study area have a large impact on the numerical values. The building-based estimates are, for example, dependent on the size distribution of buildings in the area (see [49]). It is, however, evident that the detection performance was good, except for the smallest buildings.

The quality requirements of the Finnish Topographic Database allow four errors for 100 buildings (missing or additional buildings) [54]. This suggests that if the building detection results were used as a basis for building mapping, the quality of the map could be at least near to operational requirements. With the overlap requirement of 50\%, the completeness of $96 \%$ was achieved when all buildings larger than $60 \mathrm{~m}^{2}$ were included in the analysis. In a mapping process, an operator could check all detected buildings, digitize the correct ones and discard false ones. Map buildings including missing laser data were excluded from the completeness analysis (see Section 2.2.1). In an operational process, such areas would require additional checking.

\subsection{Change Detection Results}

Change detection results obtained by using the overlap approach (the first change detection test) are presented in Figure 7. New and changed buildings for the figure were taken from the building detection results, others from the old map. The confusion matrix for the results is presented in Table 4 and the accuracy estimates as a function of building size in Figure 8. Corresponding results obtained by using the buffer approach (the second test) were presented in [73]. Examples of buildings belonging to different change classes can be seen in Figure 3 (overlap results). A summary of the accuracy estimates in numerical form both for the overlap and buffer results is presented in Table 5. Unless otherwise mentioned, the following discussion refers to the overlap results and analysis where all classes (1-5) were considered. In the discussion, it is assumed that the update process is continued by a 
human operator, who checks the buildings labeled as changed (classes 2-5) or not analyzed (6), digitizes the changes and stores them in the database. In the future, an automated process might also be possible.

The new residential area, as well as smaller groups of new buildings, are clearly discernible in the change detection results. The number of demolished buildings was small (1\% of all buildings), which is natural in a growing suburban area. Quite a few buildings were assigned to classes changed (4\%) and 1-n/n-1 (14\%). The most frequent class, however, was unchanged buildings (51\%). In the update process, the unchanged buildings could be bypassed. About $95 \%$ of all buildings labeled as unchanged were unchanged according to the reference results (correctness). High correctness of unchanged buildings is very important so that changes are not missed if the operator relies on the change detection results. Some more buildings could have been labeled as unchanged (59\% of all buildings according to the reference results). The completeness ranged from $86 \% / 96 \%$ (class 5 included/excluded) to $91 \% / 99 \%$, depending on the minimum building size.

Figure 7. Change detection results for the test areas (overlap approach used). New and changed buildings were taken from the building detection results, others from the old building map. Buildings of the old map (c) The National Land Survey of Finland 2001, permission number MML/VIR/MYY/219/09.

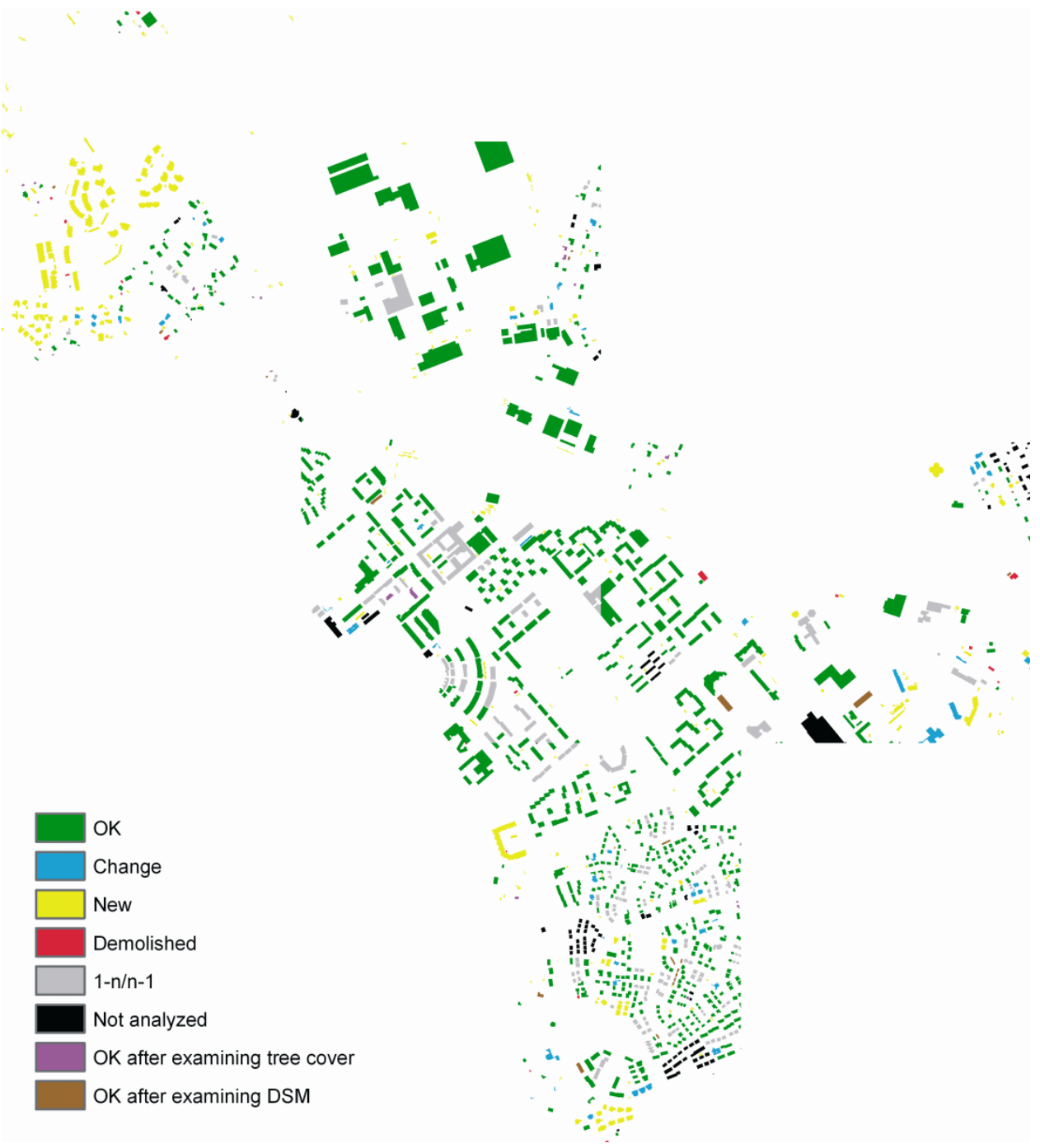


The correctness of buildings labeled as changed was 55\%, i.e., many buildings were included that were not changed in the reference data. Several of the errors, however, related to presentation of buildings on the maps (e.g., two buildings on the up-to-date map seem to be one in the DSM; a building is clearly larger in the DSM than on the maps; a changed building is a little larger in the DSM than on the up-to-date map, and it was thus classified as changed in the change detection results, but unchanged in the reference results). Real errors were often related to connection of buildings with trees or adjacent buildings. The completeness was $88 \%$ for all changed buildings, which means that real changes were identified well. It decreased for large buildings, but the number of such buildings was small, which makes the estimates unreliable.

New buildings were also well detected. The completeness was $69 \%$ for all new buildings and about $90 \%$ for buildings larger than $60 \mathrm{~m}^{2}$. New buildings not detected were thus generally small in size. There were also some errors in the largest buildings $\left(\geq 300 \mathrm{~m}^{2}\right)$. According to visual evaluation, these occurred usually for car parks or were related to the maps (e.g., a changed building and a new building in the reference results seem to be connected in the DSM and were thus classified as one changed building in the change detection results). One large new building was classified as changed because the detected building has a small overlap with an old building (demolished in the reference results). There were many false detections of new buildings, but these objects were also usually small. The correctness for all new buildings was $55 \%$ but increased to about $90 \%$ when the minimum building size was $80 \mathrm{~m}^{2}$.

Table 4. Confusion matrix for the change detection results (overlap approach used). All test areas and buildings included (threshold value $\geq 20 \mathrm{~m}^{2}$ ), class 5 included.

\begin{tabular}{ll}
\hline $\begin{array}{l}\text { Change } \\
\text { detection }\end{array}$ & Reference results \\
results & \\
\hline
\end{tabular}

\begin{tabular}{|c|c|c|c|c|c|c|c|c|c|}
\hline & OK & Change & New & $\begin{array}{l}\text { Demolished } \\
*)\end{array}$ & $\begin{array}{l}1-\mathrm{n} / \\
\mathrm{n}-1\end{array}$ & $\begin{array}{l}\text { Not } \\
\text { analyzed }\end{array}$ & $\begin{array}{l}\text { Not } \\
\text { new } \\
\text { building }\end{array}$ & Sum & $\begin{array}{l}\% \text { of } \\
\text { buildings in } \\
\text { c.d. results } \\
* * \text { ) }\end{array}$ \\
\hline $\mathrm{OK}$ & 645 & 2 & - & 13 & 22 & 0 & - & 682 & $51.0 \%$ \\
\hline Change & 19 & 29 & - & 4 & 1 & 1 & - & 54 & $4.0 \%$ \\
\hline New & - & - & 172 & - & - & Excluded & 139 & 311 & $23.3 \%$ \\
\hline Demolished & 5 & 1 & - & 13 & 0 & 0 & - & 19 & $1.4 \%$ \\
\hline $1-n / n-1$ & 82 & 1 & - & 3 & 95 & 0 & - & 181 & $13.5 \%$ \\
\hline $\begin{array}{l}\text { Not } \\
\text { analyzed }\end{array}$ & 2 & 1 & Excluded & 0 & 0 & 87 & - & 90 & $6.7 \%$ \\
\hline $\begin{array}{l}\text { Not new } \\
\text { building }\end{array}$ & - & - & 79 & - & - & - & - & 79 & - \\
\hline Sum & 753 & 34 & 251 & 33 & 118 & 88 & 139 & 1,416 & \\
\hline $\begin{array}{l}\% \text { of } \\
\text { buildings in } \\
\text { ref. results } \\
* * *)\end{array}$ & $59.0 \%$ & $2.7 \%$ & $19.7 \%$ & $2.6 \%$ & $9.2 \%$ & $6.9 \%$ & - & & $100 \%$ \\
\hline
\end{tabular}


Figure 8. Accuracy estimates for the change detection results (overlap approach used). The results are presented for different classes and buildings of different sizes. Class $5(1-n / n-1)$ was included or excluded. *) $30 \%$ of reference buildings for class 4 (demolished) were not really demolished, see text.
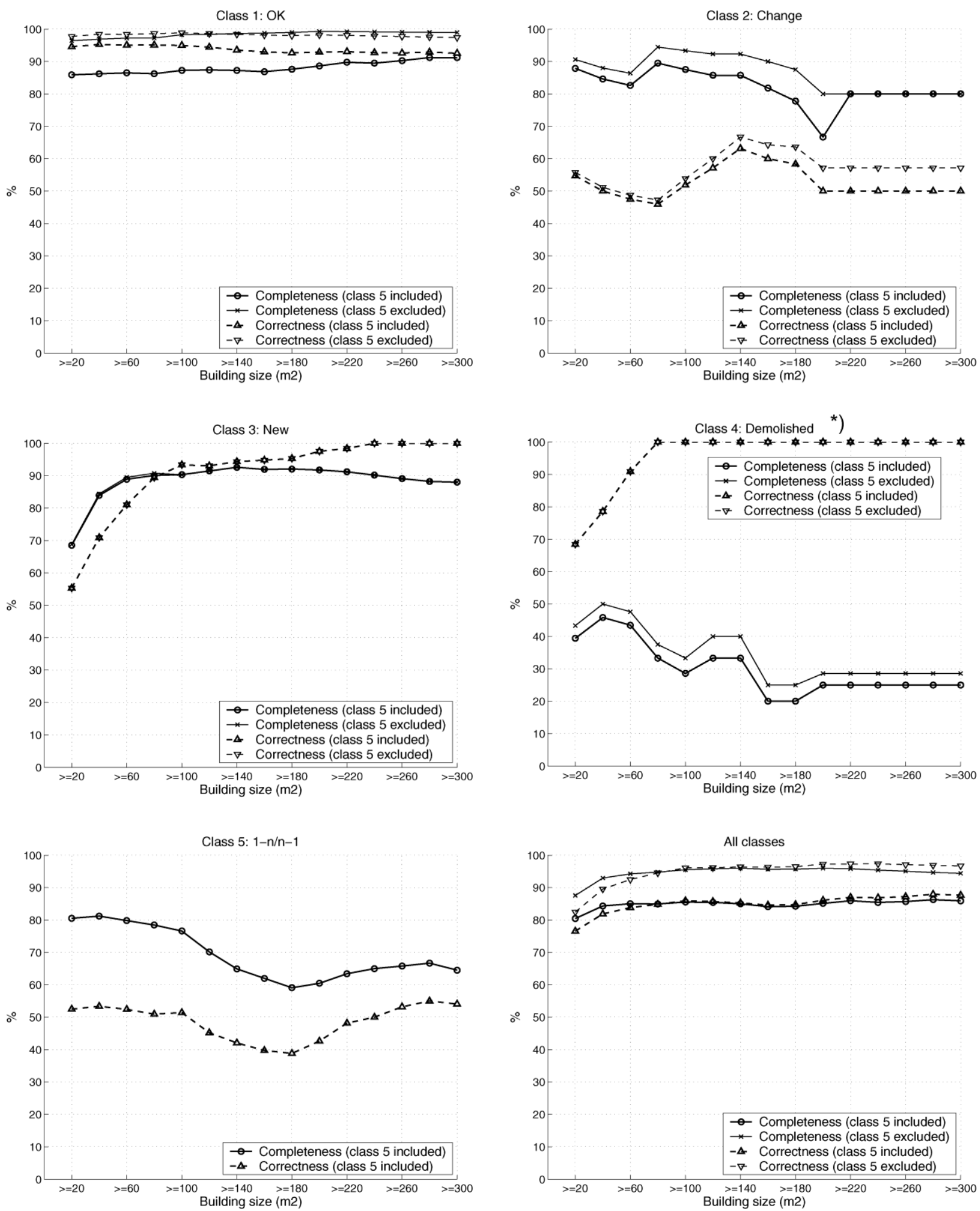
Table 5. Building-based accuracy estimates for different classes in the change detection results. All test areas included, class 5 included / excluded.

\begin{tabular}{|c|c|c|c|c|c|}
\hline $\begin{array}{l}\text { Class } \\
\text { and } \\
\text { building } \\
\text { size }\left(\mathbf{m}^{2}\right)\end{array}$ & $\begin{array}{l}\text { Change } \\
\text { detection } \\
\text { approach }\end{array}$ & $\begin{array}{l}\text { Number of } \\
\text { buildings in } \\
\text { the reference } \\
\text { results }\end{array}$ & Completeness & $\begin{array}{l}\text { Number of } \\
\text { buildings in } \\
\text { the change } \\
\text { detection } \\
\text { results }\end{array}$ & Correctness \\
\hline \multicolumn{6}{|c|}{ Class $1(\mathrm{OK})$} \\
\hline \multirow{2}{*}{$\geq 20$} & Overlap & $751 / 669$ & $85.9 \% / 96.4 \%$ & 682 / 660 & $94.6 \% / 97.7 \%$ \\
\hline & Buffers & $655 / 584$ & $71.8 \% / 80.5 \%$ & $525 / 506$ & $89.5 \% / 92.9 \%$ \\
\hline \multirow[t]{2}{*}{$\geq 100$} & Overlap & $581 / 516$ & $87.3 \% / 98.3 \%$ & $534 / 513$ & $94.9 \% / 98.8 \%$ \\
\hline & Buffers & $509 / 452$ & $71.9 \% / 81.0 \%$ & 407 / 389 & $89.9 \% / 94.1 \%$ \\
\hline \multirow[t]{2}{*}{$\geq 300$} & Overlap & $204 / 188$ & $91.2 \% / 98.9 \%$ & $201 / 191$ & $92.5 \% / 97.4 \%$ \\
\hline & Buffers & $177 / 165$ & $75.7 \% / 81.2 \%$ & $155 / 145$ & $86.5 \% / 92.4 \%$ \\
\hline \multicolumn{6}{|c|}{ Class 2 (Change) } \\
\hline \multirow{2}{*}{$\geq 20$} & Overlap & 33 / 32 & $87.9 \% / 90.6 \%$ & $53 / 52$ & $54.7 \% / 55.8 \%$ \\
\hline & Buffers & $118 / 108$ & $69.5 \% / 75.9 \%$ & $201 / 197$ & $40.8 \% / 41.6 \%$ \\
\hline \multirow{2}{*}{$\geq 100$} & Overlap & $16 / 15$ & $87.5 \% / 93.3 \%$ & $27 / 26$ & $51.9 \% / 53.8 \%$ \\
\hline & Buffers & $88 / 79$ & $69.3 \% / 77.2 \%$ & $153 / 149$ & $39.9 \% / 40.9 \%$ \\
\hline \multirow[t]{2}{*}{$\geq 300$} & Overlap & $5 / 5$ & $80.0 \% / 80.0 \%$ & $8 / 7$ & $50.0 \% / 57.1 \%$ \\
\hline & Buffers & $32 / 28$ & $65.6 \% / 75.0 \%$ & $54 / 53$ & $38.9 \% / 39.6 \%$ \\
\hline \multicolumn{6}{|c|}{ Class 3 (New) } \\
\hline \multirow{2}{*}{$\geq 20$} & Overlap & $251 / 250$ & $68.5 \% / 68.8 \%$ & $311 / 311$ & $55.3 \% / 55.3 \%$ \\
\hline & Buffers & $250 / 249$ & $68.4 \% / 68.7 \%$ & $310 / 310$ & $55.2 \% / 55.2 \%$ \\
\hline \multirow{2}{*}{$\geq 100$} & Overlap & $124 / 124$ & $90.3 \% / 90.3 \%$ & $120 / 120$ & $93.3 \% / 93.3 \%$ \\
\hline & Buffers & $123 / 123$ & $90.2 \% / 90.2 \%$ & $119 / 119$ & $93.3 \% / 93.3 \%$ \\
\hline \multirow[t]{2}{*}{$\geq 300$} & Overlap & $50 / 50$ & $88.0 \% / 88.0 \%$ & 44 / 44 & $100.0 \% / 100.0 \%$ \\
\hline & Buffers & 49 / 49 & $87.8 \% / 87.8 \%$ & 43 / 43 & $100.0 \% / 100.0 \%$ \\
\hline \multicolumn{6}{|c|}{ Class 4 (Demolished) $*$ ) } \\
\hline \multirow[t]{2}{*}{$\geq 20$} & Overlap & $33 / 30$ & $39.4 \% / 43.3 \%$ & $19 / 19$ & $68.4 \% / 68.4 \%$ \\
\hline & Buffers & $31 / 28$ & $41.9 \% / 46.4 \%$ & $17 / 17$ & $76.5 \% / 76.5 \%$ \\
\hline \multirow[t]{2}{*}{$\geq 100$} & Overlap & $14 / 12$ & $28.6 \% / 33.3 \%$ & $4 / 4$ & $100.0 \% / 100.0 \%$ \\
\hline & Buffers & $13 / 11$ & $30.8 \% / 36.4 \%$ & $4 / 4$ & $100.0 \% / 100.0 \%$ \\
\hline \multirow[t]{2}{*}{$\geq 300$} & Overlap & $8 / 7$ & $25.0 \% / 28.6 \%$ & $2 / 2$ & $100.0 \% / 100.0 \%$ \\
\hline & Buffers & $8 / 7$ & $25.0 \% / 28.6 \%$ & $2 / 2$ & $100.0 \% / 100.0 \%$ \\
\hline \multicolumn{6}{|c|}{ Class 5 (1-n/n-1) } \\
\hline \multirow[t]{2}{*}{$\geq 20$} & Overlap & 118 & $80.5 \%$ & 181 & $52.5 \%$ \\
\hline & Buffers & 118 & $80.5 \%$ & 179 & $53.1 \%$ \\
\hline \multirow[t]{2}{*}{$\geq 100$} & Overlap & 94 & $76.6 \%$ & 140 & $51.4 \%$ \\
\hline & Buffers & 94 & $76.6 \%$ & 140 & $51.4 \%$ \\
\hline \multirow[t]{2}{*}{$\geq 300$} & Overlap & 31 & $64.5 \%$ & 37 & $54.1 \%$ \\
\hline & Buffers & 31 & $64.5 \%$ & 37 & $54.1 \%$ \\
\hline \multicolumn{6}{|l|}{ All classes } \\
\hline \multirow[t]{2}{*}{$\geq 20$} & Overlap & $1,186 / 981$ & $80.4 \% / 87.6 \%$ & $1,246 / 1,042$ & $76.6 \% / 82.4 \%$ \\
\hline & Buffers & 1,172 / 969 & $70.9 \% / 76.0 \%$ & $1,232 / 1,030$ & $67.5 \% / 71.5 \%$ \\
\hline \multirow[t]{2}{*}{$\geq 100$} & Overlap & 829 / 667 & $85.5 \% / 95.5 \%$ & 825 / 663 & $85.9 \% / 96.1 \%$ \\
\hline & Buffers & 827 / 665 & $74.2 \% / 81.5 \%$ & 823 / 661 & $74.6 \% / 82.0 \%$ \\
\hline \multirow[t]{2}{*}{$\geq 300$} & Overlap & $298 / 250$ & $85.9 \% / 94.4 \%$ & $292 / 244$ & $87.7 \% / 96.7 \%$ \\
\hline & Buffers & $297 / 249$ & $74.1 \% / 80.3 \%$ & $291 / 243$ & $75.6 \% / 82.3 \%$ \\
\hline
\end{tabular}

*) 10 of the reference buildings for class 4 (demolished) were not really demolished (see text).

The correctness of demolished buildings was high, except for the smallest buildings (68\% for all buildings, and about $90 \%$ for buildings larger than $60 \mathrm{~m}^{2}$ (Figure 8)). The completeness seems low 
(39\% for all buildings), but these results are misleading. The number of buildings in this class was small, and problems on the maps have a large effect on the results. Visual inspection of the demolished buildings in the reference results showed that 10/33 (30\%) of them were not really demolished. Nine buildings were not included in the up-to-date raster map because they were missing, smaller than 20 $\mathrm{m}^{2}$ or not presented as closed polygons on the original vector map. Five of these were car parks or other large constructions, and four were small buildings. One large building was probably mislocated on the old map. If these 10 buildings are excluded from the analysis, the completeness rises to 57\% (all buildings included) and the errors occur in small buildings (most of them $<100 \mathrm{~m}^{2}$, all $<200 \mathrm{~m}^{2}$ ). It should be noted that the erroneous demolished buildings in the reference results also affect the accuracy estimates of other classes.

About $14 \%$ of buildings were assigned to class 5 (1-n/n-1). In the reference results, the percentage was $9 \%$. As already discussed, this class is problematic because it can occur in many different cases: due to real changes, due to representation of buildings on the map, or due to errors in the building detection. When all buildings are considered, the completeness of the class was $81 \%$. For larger buildings it decreased, which indicates that correct detection of the class was not easier for large buildings. The correctness was 52\%. Many buildings that were unchanged according to the reference results were assigned to this class. This generally related to problems in building detection, such as missing parts in buildings or nearby buildings connected to each other, but sometimes also to the maps.

In the accuracy estimation, classes 7 (OK after examining tree cover) and 8 (OK after examining DSM) were included in class 1 (unchanged). Table 6 shows a separate comparison between buildings assigned to these classes and the reference results. Most buildings in classes 7 and 8 were unchanged in the reference results, and the effect of the additional correction rules was thus mainly positive. According to visual evaluation, the rule based on the DSM was particularly useful in detecting car parks missed in the building detection stage (see Figure 3f). A few buildings assigned to classes 7 and 8 were demolished or changed in the reference results. These changes were missed due to the correction rules. Sloping areas are problematic for the DSM rule because the height difference on the ground can exceed the threshold value used to indicate a building. The problem with the tree cover rule is that old, ramshackle buildings, which are more likely to be demolished than other buildings, are often covered by large trees. Depending on the objectives of the update process, it might be best that the operator also checks buildings assigned to classes 7 and 8 .

Considering all classes and buildings, the completeness and correctness were $80 \%$ and $77 \%$, respectively. For buildings larger than $60 \mathrm{~m}^{2}$, they were about $85 \%$ (Figure 8). This is a satisfactory result, remembering that all the accuracy estimates presented here include some uncertainty related to the maps. Numerically, the results obtained for unchanged and changed buildings by using the overlap approach were better than those obtained by using the buffer approach. This was related to the smaller number of changes to detect. The buffer approach is better suited to the detection of subtle changes in the buildings than the overlap approach. On the other hand, the basic idea of carrying out change detection after building detection is probably most effective when the goal is only to detect the major changes. If the goal is to detect subtle changes in the shape of the buildings, it would be better to first carry out the building extraction process further, i.e., to determine the exact boundaries of the buildings. 
Table 6. Reference results for buildings classified as OK after applying the special correction rules (classes 7 and 8). All test areas included. The results are presented for the overlap / buffer approach.

\begin{tabular}{lcccccc}
\hline Change detection results & OK & Change & New & Demolished & $1-n / n-1$ & $\begin{array}{l}\text { Not } \\
\text { analyzed }\end{array}$ \\
\hline & $15 / 34$ & $0 / 1$ & $0 / 0$ & $2 / 2$ & $0 / 0$ & $0 / 1$ \\
\hline $\begin{array}{l}\text { OK after examining tree } \\
\text { cover }\end{array}$ & $16 / 14$ & $1 / 1$ & $0 / 0$ & $\begin{array}{c}7 / 7 \\
*)\end{array}$ & $0 / 0$ & $0 / 2$ \\
\hline $\begin{array}{l}\text { OK after examining DSM } \\
\text { n }\end{array}$ & & & & \\
\hline
\end{tabular}

*) Includes 3 buildings that were not really demolished.

As discussed above, the change detection method found real changes rather well. The main problem was false detection of changes, i.e., new, changed, and 1-n/n-1 buildings. However, there were not many false detections of demolished buildings. The trend that completeness in detecting changes was higher than correctness was similar to that found in many other change detection studies (e.g., $[8,10])$. Completeness in detecting changes is also more important than correctness if the updating continues manually. A moderate number of false detections can be checked visually and bypassed, but finding missing changes is time consuming and can defeat the object of using an automated method.

From Table 4, it can be calculated that a total of 245 buildings that were unchanged or not a new building in the reference results were assigned to some of the change classes (2-5) in the change detection. This is $18 \%$ of all buildings in the change detection results. These buildings would require checking by an operator, even though they have not changed. From Table 4 it can also be calculated that the number of buildings that belonged to a change class (2-5) in the reference results but were labeled as unchanged or not detected as a new building was 116, which is $9 \%$ of all reference buildings. These buildings would remain uncorrected in the update, assuming that the operator would check buildings assigned to classes 2-6. The percentage is a little larger than the $4 \%$ allowed in the quality requirements of the Topographic Database (missing and additional buildings; [54]), but it is affected by the uncertainty of the reference data, and includes many small buildings that are normally presented on the city base map but not in the Topographic Database, and also includes some changed and 1-n/n-1 buildings. As discussed above, most errors in new and demolished buildings occurred in small buildings. When assessing the usefulness of automated change detection, it must also be noted that even if some changes are missed, the database resulting from updating will be more accurate than the version before updating. If the update process can be made faster and easier, this can also have positive effects on the quality of the data. Practical tests are needed to finally show if the methods are feasible and accurate enough to benefit operational work. Comparisons of quality between automatic and visual change detection results would also be important.

\section{Conclusions and Further Development}

Methods for automatic detection of buildings and changes in buildings were developed and thoroughly tested by using airborne laser scanner and digital aerial image data from a $5 \mathrm{~km}^{2}$ suburban 
area. Two real building maps of the area-an old one and an up-to-date one-were used to evaluate the quality of the results.

The building detection method is based on region-based segmentation and classification but also utilizes classification of laser points to distinguish ground segments. To distinguish buildings from trees, the classification tree method is used. The results were in agreement with previous studies and showed that buildings can be detected automatically with relatively good accuracy. In pixel-based comparison with the up-to-date map data, the mean accuracy of buildings was $89 \%$. The pixel-based estimates are affected by differences between the map and aerial data, and the real accuracy is thus likely to be somewhat higher. Building-based comparison with the map showed that the detection performance of the method was generally good. Errors occurred mainly in small buildings and special cases, such as car parks located on a hill slope, which are difficult to detect automatically. When all buildings larger than $60 \mathrm{~m}^{2}$ were included in the analysis and an overlap of $50 \%$ between reference buildings and detected buildings was required, both completeness and correctness were $96 \%$. This accuracy level could lead to a building map that is compatible with operational quality requirements.

The change detection method compares detected building objects with those on a map and classifies buildings as unchanged, changed, new, demolished and 1-n/n-1 buildings. For the detection of changed buildings, overlap percentages or buffers are used. Additional correction rules relying on the existing map data can be used to decrease the number of misclassifications. Considering the five classes listed above and all buildings larger than $20 \mathrm{~m}^{2}$, the completeness and correctness of the change detection results were $80 \%$ and $77 \%$, respectively (the overlap approach was used to detect changed buildings). For buildings larger than $60 \mathrm{~m}^{2}$, the estimates were about $85 \%$. About $50 \%$ of buildings in the study area were detected as unchanged, with correctness of $95 \%$, and real changes were found relatively well (e.g., completeness $69 \%, 88 \%$ and $81 \%$ for all new, changed and $1-\mathrm{n} / \mathrm{n}-1$ buildings, respectively). The main problem was false detection of changes, especially new, changed, and $1-n / n-1$ buildings. The total number of false changes, however, was moderate (18\% of all buildings). In the case of new and demolished buildings, errors occurred mainly in small buildings. In the case of changed and 1-n/n-1 buildings, errors also occurred in larger buildings. They were related, for example, to connection of buildings with trees or adjacent buildings but sometimes also to the representation of buildings on the maps.

To improve the change detection results, further studies should concentrate on the problematic cases and on the testing of new and potentially useful datasets, such as full-waveform laser scanner data, which are expected to improve the automatic classification of objects through additional features extracted (e.g., echo width and backscattering coefficient). For example, connection of buildings with adjacent trees could be diminished by further analysis of aerial image or waveform data for the detected buildings. On the other hand, this problem can also be diminished by simply using laser scanner data from leaf-off conditions. The use of laser scanner data with a higher point density would be useful to better distinguish adjacent buildings from each other and to improve the shape of the detected buildings. It might also improve the results for small buildings. Classification of different objects, such as roads, could decrease the number of false detections of buildings. The number of false detections of small new buildings might also be reduced by using specific shape criteria for buildings not presented on the old map. However, caution is needed with such criteria to avoid missing real new buildings. It is likely that many of the false detections are easy for a human operator to recognize 
visually and thus bypass. Searching for undetected changes is more difficult and contrary to the basic idea of using automated change detection.

In addition to testing new datasets and developing more advanced methods to tackle the problematic cases, further tests should be carried out to show if the methods are useful and accurate enough for operational work. Ideally, operators updating a map database could bypass the unchanged buildings and concentrate on checking and correcting the changed ones, which might lead to significant savings in time and costs. Practical tests, however, are needed to confirm this. Performance of the methods in the case of sparse laser scanner data and aerial images with lower spatial resolution, which are used for operational countrywide mapping, should also be investigated. Another topic requiring further study is the applicability of classification rules in different areas. It is likely that classification rules created for building detection in one area can be utilized in other similar areas if the data have similar characteristics. Changes in the data, however, require changes in the rules. Rules can be created automatically by using the classification tree method and an up-to-date building map of a training area, which was the approach used in this study, but manual improvement of the rules is also possible.

In this study, we investigated buildings, which are very important objects for updating, but there are also many other objects in map databases that need to be updated. The basic ideas and elements of this study, such as the classification tree method, could be utilized to also develop change detection methods for other objects. The change detection principles and rules, however, need to be defined separately by taking into account the specific characteristics of different objects.

\section{Acknowledgements}

The authors wish to thank Kimmo Nurminen for his advice in ortho rectification of the aerial images, Eija Honkavaara for her contribution in the acquisition of the images, the reviewers of the manuscript for their useful comments, and the National Land Survey of Finland and the city of Espoo for the map data.

\section{References}

1. Petzold, B.; Walter, V. Revision of topographic databases by satellite images. In Proceedings of the ISPRS Workshop: Sensors and Mapping from Space 1999, Hannover, Germany, September 27-30, 1999; Available online: http://www.ipi.uni-hannover.de/fileadmin/institut/pdf/petzold.pdf (accessed on April 15, 2010).

2. Eidenbenz, C.; Käser, C.; Baltsavias, E. ATOMI—automated reconstruction of topographic objects from aerial images using vectorized map information. In Proceedings of the XIX ${ }^{\text {th }}$ ISPRS Congress, Amsterdam, The Netherlands, July 16-23, 2000; In International Archives of Photogrammetry and Remote Sensing, Vol. XXXIII, Part B3, pp. 462-471.

3. Armenakis, C.; Leduc, F.; Cyr, I.; Savopol, F.; Cavayas, F. A comparative analysis of scanned maps and imagery for mapping applications. ISPRS J. Photogramm. Remote Sensing 2003, 57, 304-314.

4. Knudsen, T.; Olsen, B.P. Automated change detection for updates of digital map databases. Photogramm. Eng. Remote Sensing 2003, 69, 1289-1296. 
5. Busch, A.; Gerke, M.; Grünreich, D.; Heipke, C.; Liedtke, C.-E.; Müller, S. Automated verification of a topographic reference dataset: System design and practical results. In Proceedings of the $X X^{\text {th }}$ ISPRS Congress, Istanbul, Turkey, July 12-23, 2004; In International Archives of Photogrammetry, Remote Sensing and Spatial Information Sciences, Vol. XXXV, Part B2, pp. 735-740.

6. Steinnocher, K.; Kressler, F. Change detection (Final report of a EuroSDR project). EuroSDR Official Publication No 50; EuroSDR: Frankfurt, Germany, 2006; pp. 111-182.

7. Champion, N. 2D building change detection from high resolution aerial images and correlation digital surface models. In Proceedings of PIA07-Photogrammetric Image Analysis, Munich, Germany, September 19-21, 2007; In International Archives of Photogrammetry, Remote Sensing and Spatial Information Sciences, Vol. XXXVI, Part 3/W49A, pp. 197-202.

8. Holland, D.A.; Sanchez-Hernandez, C.; Gladstone, C. Detecting changes to topographic features using high resolution imagery. In Proceedings of the XXI ${ }^{\text {st }}$ ISPRS Congress, Beijing, China, July 3-11, 2008; In International Archives of Photogrammetry, Remote Sensing and Spatial Information Sciences, Vol. XXXVII, Part B4, pp. 1153-1158.

9. Rottensteiner, F. Building change detection from digital surface models and multi-spectral images. In Proceedings of PIA07-Photogrammetric Image Analysis, Munich, Germany, September 19-21, 2007; In International Archives of Photogrammetry, Remote Sensing and Spatial Information Sciences, Vol. XXXVI, Part 3/W49B, pp. 145-150.

10. Champion, N.; Rottensteiner, F.; Matikainen, L.; Liang, X.; Hyyppä, J.; Olsen, B.P. A test of automatic building change detection approaches. In Proceedings of CMRT09: Object Extraction for 3D City Models, Road Databases and Traffic Monitoring-Concepts, Algorithms and Evaluation, Paris, France, September 3-4, 2009; In International Archives of Photogrammetry, Remote Sensing and Spatial Information Sciences, Vol. XXXVIII, Part 3/W4, pp. 145-150.

11. Murakami, H.; Nakagawa, K.; Hasegawa, H.; Shibata, T.; Iwanami, E. Change detection of buildings using an airborne laser scanner. ISPRS J. Photogramm. Remote Sensing 1999, 54, 148-152.

12. Vögtle, T.; Steinle, E. Detection and recognition of changes in building geometry derived from multitemporal laserscanning data. In Proceedings of the $X X^{\text {th }}$ ISPRS Congress, Istanbul, Turkey, July 12-23, 2004; In International Archives of Photogrammetry, Remote Sensing and Spatial Information Sciences, Vol. XXXV, Part B2, pp. 428-433.

13. Jung, F. Detecting building changes from multitemporal aerial stereopairs. ISPRS J. Photogramm. Remote Sensing 2004, 58, 187-201.

14. Vu, T.T.; Matsuoka, M.; Yamazaki, F. LIDAR-based change detection of buildings in dense urban areas. In Proceedings of IGARSS'04, Anchorage, AK, USA, September 20-24, 2004; Volume 5, pp. 3413-3416.

15. Butkiewicz, T.; Chang, R.; Wartell, Z.; Ribarsky, W. Visual analysis and semantic exploration of urban LIDAR change detection. Comput. Graph. Forum 2008, 27, 903-910.

16. Nakagawa, M.; Shibasaki, R. Building change detection using 3-D texture model. In Proceedings of the XXI It ISPRS Congress, Beijing, China, July 3-11, 2008; In International Archives of Photogrammetry, Remote Sensing and Spatial Information Sciences, Vol. XXXVII, Part B3A, pp. 173-178. 
17. Hoffmann, A.; Van der Vegt, J.W.; Lehmann, F. Towards automated map updating: Is it feasible with new digital data-acquisition and processing techniques? In Proceedings of the XIX ${ }^{\text {th }}$ ISPRS Congress, Amsterdam, The Netherlands, July 16-23, 2000; In International Archives of Photogrammetry and Remote Sensing, Vol. XXXIII, Part B2, pp. 295-302.

18. Knudsen, T.; Olsen, B.P. Detection of buildings in colour and colour-infrared aerial photos for semi-automated revision of topographic databases. In Proceedings of the ISPRS Commission III Symposium: Photogrammetric Computer Vision, Graz, Austria, September 9-13, 2002; In International Archives of Photogrammetry, Remote Sensing and Spatial Information Sciences, Vol. XXXIV, Part 3B, pp. 120-125.

19. Olsen, B.P. Automatic change detection for validation of digital map databases. In Proceedings of the $X X^{\text {th }}$ ISPRS Congress, Istanbul, Turkey, July 12-23, 2004; In International Archives of Photogrammetry, Remote Sensing and Spatial Information Sciences, Vol. XXXV, Part B2, pp. 569-574.

20. Matikainen, L.; Hyyppä, J.; Hyyppä, H. Automatic detection of buildings from laser scanner data for map updating. In Proceedings of the ISPRS Working Group III/3 Workshop: 3-D Reconstruction from Airborne Laserscanner and InSAR Data, Dresden, Germany, October 8-10, 2003; In International Archives of Photogrammetry, Remote Sensing and Spatial Information Sciences, Vol. XXXIV, Part 3/W13, pp. 218-224.

21. Matikainen, L.; Hyyppä, J.; Kaartinen, H. Automatic detection of changes from laser scanner and aerial image data for updating building maps. In Proceedings of the $X X^{\text {th }}$ ISPRS Congress, Istanbul, Turkey, July 12-23, 2004; In International Archives of Photogrammetry, Remote Sensing and Spatial Information Sciences, Vol. XXXV, Part B2, pp. 434-439.

22. Vosselman, G.; Gorte, B.G.H.; Sithole, G. Change detection for updating medium scale maps using laser altimetry. In Proceedings of the $X X^{\text {th }}$ ISPRS Congress, Istanbul, Turkey, July 12-23, 2004; In International Archives of Photogrammetry, Remote Sensing and Spatial Information Sciences, Vol. XXXV, Part B3, pp. 207-212.

23. Vosselman, G.; Kessels, P.; Gorte, B. The utilisation of airborne laser scanning for mapping. Int. J. Appl. Earth Obs. Geoinf. 2005, 6, 177-186.

24. Rottensteiner, F. Automated updating of building data bases from digital surface models and multi-spectral images: Potential and limitations. In Proceedings of the XXI ${ }^{\text {st }}$ ISPRS Congress, Beijing, China, July 3-11, 2008; In International Archives of Photogrammetry, Remote Sensing and Spatial Information Sciences, Vol. XXXVII, Part B3A, pp. 265-270.

25. Ceresola, S.; Fusiello, A.; Bicego, M.; Belussi, A.; Murino, V. Automatic updating of urban vector maps. In Image Analysis and Processing-ICIAP 2005; Roli, F., Vitulano, S., Eds.; Springer-Verlag: Berlin / Heidelberg, Germany, 2005; Lecture Notes in Computer Science Series, Volume 3617/2005, pp. 1133-1139.

26. Bouziani, M.; Goïta, K.; He, D.-C. Automatic change detection of buildings in urban environment from very high spatial resolution images using existing geodatabase and prior knowledge. ISPRS J. Photogramm. Remote Sensing 2010, 65, 143-153.

27. Hug, C. Extracting artificial surface objects from airborne laser scanner data. In Automatic Extraction of Man-Made Objects from Aerial and Space Images (II); Gruen, A., Baltsavias, E.P., Henricsson, O., Eds.; Birkhäuser Verlag: Basel, Switzerland, 1997; pp. 203-212. 
28. Brunn, A.; Weidner, U. Hierarchical Bayesian nets for building extraction using dense digital surface models. ISPRS J. Photogramm. Remote Sensing 1998, 53, 296-307.

29. Haala, N.; Brenner, C. Extraction of buildings and trees in urban environments. ISPRS J. Photogramm. Remote Sensing 1999, 54, 130-137.

30. Morgan, M.; Tempfli, K. Automatic building extraction from airborne laser scanning data. In Proceedings of the XIX ${ }^{\text {th }}$ ISPRS Congress, Amsterdam, The Netherlands, July 16-23, 2000; In International Archives of Photogrammetry and Remote Sensing, Vol. XXXIII, Part B3, pp. 616-623.

31. Oude Elberink, S.; Maas, H.-G. The use of anisotropic height texture measures for the segmentation of airborne laser scanner data. In Proceedings of the XIX ${ }^{\text {th }}$ ISPRS Congress, Amsterdam, The Netherlands, July 16-23, 2000; In International Archives of Photogrammetry and Remote Sensing, Vol. XXXIII, Part B3, pp. 678-684.

32. Vögtle, T.; Steinle, E. 3D modelling of buildings using laser scanning and spectral information. In Proceedings of the XIX ${ }^{\text {th }}$ ISPRS Congress, Amsterdam, The Netherlands, July 16-23, 2000; In International Archives of Photogrammetry and Remote Sensing, Vol. XXXIII, Part B3, pp. 927-934.

33. Alharthy, A.; Bethel, J. Heuristic filtering and 3D feature extraction from lidar data. In Proceedings of the ISPRS Commission III Symposium: Photogrammetric Computer Vision, Graz, Austria, September 9-13, 2002; In International Archives of Photogrammetry, Remote Sensing and Spatial Information Sciences, Vol. XXXIV, Part 3A, pp. 29-34.

34. Tóvári, D.; Vögtle, T. Classification methods for 3D objects in laserscanning data. In Proceedings of the XX $X^{\text {th }}$ ISPRS Congress, Istanbul, Turkey, July 12-23, 2004; In International Archives of Photogrammetry, Remote Sensing and Spatial Information Sciences, Vol. XXXV, Part B3, pp. 408-413.

35. Ma, R. DEM generation and building detection from lidar data. Photogramm. Eng. Remote Sensing 2005, 71, 847-854.

36. Rottensteiner, F.; Trinder, J.; Clode, S.; Kubik, K. Using the Dempster-Shafer method for the fusion of LIDAR data and multi-spectral images for building detection. Inf. Fusion 2005, 6, 283-300.

37. Forlani, G.; Nardinocchi, C.; Scaioni, M.; Zingaretti, P. Complete classification of raw LIDAR data and 3D reconstruction of buildings. Pattern Anal. Appl. 2006, 8, 357-374.

38. Zhang, K.; Yan, J.; Chen, S.-C. Automatic construction of building footprints from airborne LIDAR data. IEEE Trans. Geosci. Remote Sens. 2006, 44, 2523-2533.

39. Miliaresis, G.; Kokkas, N. Segmentation and object-based classification for the extraction of the building class from LIDAR DEMs. Comput. Geosci. 2007, 33, 1076-1087.

40. Sohn, G.; Dowman, I. Data fusion of high-resolution satellite imagery and LiDAR data for automatic building extraction. ISPRS J. Photogramm. Remote Sensing 2007, 62, 43-63.

41. Lee, D.H.; Lee, K.M.; Lee, S.U. Fusion of lidar and imagery for reliable building extraction. Photogramm. Eng. Remote Sensing 2008, 74, 215-225.

42. Meng, X.; Wang, L.; Currit, N. Morphology-based building detection from airborne lidar data. Photogramm. Eng. Remote Sensing 2009, 75, 437-442.

43. Vu, T.T.; Yamazaki, F.; Matsuoka, M. Multi-scale solution for building extraction from LiDAR and image data. Int. J. Appl. Earth Obs. Geoinf. 2009, 11, 281-289. 
44. ISPRS. Proceedings of the XXI $I^{\text {st }}$ ISPRS Congress, Beijing, China, July 3-11, 2008; In International Archives of Photogrammetry, Remote Sensing and Spatial Information Sciences, Vol. XXXVII; Available online: http://www.isprs.org/publications/archives.aspx (accessed on April 15, 2010).

45. Mallet, C.; Bretar, F.; Soergel, U. Analysis of full-waveform lidar data for classification of urban areas. Photogrammetrie-Fernerkundung-Geoinformation 2008, No. 5/2008, 337-349.

46. Pfeifer, N.; Rutzinger, M.; Rottensteiner, F.; Muecke, W.; Hollaus, M. Extraction of building footprints from airborne laser scanning: Comparison and validation techniques. In Proceedings of the 2007 IEEE Urban Remote Sensing Joint Event, URBAN 2007-URS 2007, Paris, France, April 11-13, 2007.

47. Rottensteiner, F.; Trinder, J.; Clode, S.; Kubik, K. Building detection by fusion of airborne laser scanner data and multi-spectral images: Performance evaluation and sensitivity analysis. ISPRS J. Photogramm. Remote Sensing 2007, 62, 135-149.

48. Khoshelham, K.; Nardinocchi, C.; Frontoni, E.; Mancini, A.; Zingaretti, P. Performance evaluation of automated approaches to building detection in multi-source aerial data. ISPRS J. Photogramm. Remote Sensing 2010, 65, 123-133.

49. Rutzinger, M.; Rottensteiner, F.; Pfeifer, N. A comparison of evaluation techniques for building extraction from airborne laser scanning. IEEE J. Selected Topics Appl. Earth Obs. Remote Sens. 2009, 2, 11-20.

50. Terrasolid. Terrasolid Ltd.: Jyväskylä, Finland, Available online: http://www.terrasolid.fi/ (accessed on April 15, 2010).

51. Axelsson, P. DEM generation from laser scanner data using adaptive TIN models. In Proceedings of the XIX ${ }^{\text {th }}$ ISPRS Congress, Amsterdam, The Netherlands, July 16-23, 2000; In International Archives of Photogrammetry and Remote Sensing, Vol. XXXIII, Part B4, pp. 110-117.

52. Intergraph. Intergraph Corporation: Huntsville, AL, USA, Available online: http://www.intergraph.com/sgi/products/default.aspx (accessed on April 15, 2010).

53. ERDAS. ERDAS Inc.: Norcross, GA, USA, Available online: http://www.erdas.com/ (accessed on April 15, 2010).

54. NLSF (Maanmittauslaitos, National Land Survey of Finland). Maastotietojen laatumalli; NLSF: Helsinki, Finland, 1995 (in Finnish); Available online: http://www.maanmittauslaitos.fi/ Tietoa_maasta/Digitaaliset_tuotteet/Maastotietokanta/ (accessed on April 15, 2010).

55. Definiens. Definiens Professional 5 User Guide; Definiens AG: München, Germany, 2006.

56. Definiens. Definiens Professional 5 Reference Book; Definiens AG: München, Germany, 2006.

57. Definiens. Definiens AG: München, Germany, Available online: http://www.definiens.com/ (accessed on April 15, 2010).

58. Baatz, M.; Schäpe, A. Multiresolution segmentation-An optimization approach for high quality multi-scale image segmentation. In Angewandte Geographische Informationsverarbeitung XII: Beiträge zum AGIT-Symposium Salzburg 2000; Strobl, J., Blaschke, T., Griesebner, G., Eds.; Wichmann: Heidelberg, Germany, 2000; pp. 12-23.

59. The MathWorks. The MathWorks, Inc.: Natick, MA, USA, Available online: http://www.mathworks.com/ (accessed on April 15, 2010). 
60. Matikainen, L.; Hyyppä, J.; Kaartinen, H. Comparison between first pulse and last pulse laser scanner data in the automatic detection of buildings. Photogramm. Eng. Remote Sensing 2009, 75, 133-146.

61. Breiman, L.; Friedman, J.H.; Olshen, R.A.; Stone, C.J. Classification and Regression Trees; Wadsworth, Inc.: Belmont, CA, USA, 1984.

62. Friedl, M.A.; Brodley, C.E. Decision tree classification of land cover from remotely sensed data. Remote Sens. Environ. 1997, 61, 399-409.

63. Lawrence, R.L.; Wright, A. Rule-based classification systems using classification and regression tree (CART) analysis. Photogramm. Eng. Remote Sensing 2001, 67, 1137-1142.

64. Thomas, N.; Hendrix, C.; Congalton, R.G. A comparison of urban mapping methods using highresolution digital imagery. Photogramm. Eng. Remote Sensing 2003, 69, 963-972.

65. Hodgson, M.E.; Jensen, J.R.; Tullis, J.A.; Riordan, K.D.; Archer, C.M. Synergistic use of lidar and color aerial photography for mapping urban parcel imperviousness. Photogramm. Eng. Remote Sensing 2003, 69, 973-980.

66. Ducic, V.; Hollaus, M.; Ullrich, A.; Wagner, W.; Melzer, T. 3D vegetation mapping and classification using full-waveform laser scanning. In Proceedings of the International Workshop: 3D Remote Sensing in Forestry, Vienna, Austria, February 14-15, 2006; pp. 222-228; Available online: http://www.rali.boku.ac.at/fileadmin/_H85/H857/workshops/3drsforestry/Proceedings_ 3D_Remote_Sensing_2006_rev_20070129.pdf (accessed on April 15, 2010).

67. Matikainen, L. Improving automation in rule-based interpretation of remotely sensed data by using classification trees. Photogramm. J. Fin. 2006, 20, 5-20.

68. Zingaretti, P.; Frontoni, E.; Forlani, G.; Nardinocchi, C. Automatic extraction of LIDAR data classification rules. In Proceedings of the $14^{\text {th }}$ IEEE International Conference on Image Analysis and Processing, ICIAP 2007, Modena, Italy, September 10-14, 2007.

69. Im, J.; Jensen, J.R.; Hodgson, M.E. Object-based land cover classification using high-posting-density LiDAR data. GISci. Remote Sens. 2008, 45, 209-228.

70. The MathWorks. Online documentation for Statistics Toolbox, Version 4.0; The MathWorks, Inc.: Natick, MA, USA, 2003.

71. Haralick, R.M.; Shanmugam, K.; Dinstein, I. Textural features for image classification. IEEE Trans. Syst. Man Cybern. 1973, SMC-3, 610-621.

72. Matikainen, L.; Kaartinen, H.; Hyyppä, J. Classification tree based building detection from laser scanner and aerial image data. In Proceedings of the ISPRS Workshop: Laser Scanning 2007 and SilviLaser 2007, Espoo, Finland, September 12-14, 2007; In International Archives of Photogrammetry, Remote Sensing and Spatial Information Sciences, Vol. XXXVI, Part 3/W52, pp. 280-287.

73. Matikainen, L.; Hyyppä, J.; Ahokas, E.; Markelin, L.; Kaartinen, H. An improved approach for automatic detection of changes in buildings. In Proceedings of the ISPRS Workshop: Laserscanning'09, Paris, France, September 1-2, 2009; In International Archives of Photogrammetry, Remote Sensing and Spatial Information Sciences, Vol. XXXVIII, Part 3/W8, pp. 61-67. 
74. Uitermark, H.; van Oosterom, P.; Mars, N.; Molenaar, M. Propagating updates: Finding corresponding objects in a multi-source environment. In Proceedings of the $8^{\text {th }}$ International Symposium on Spatial Data Handling, Vancouver, Canada, July 11-15, 1998; pp. 580-591.

75. Badard, T. On the automatic retrieval of updates in geographic databases based on geographic data matching tools. In Proceedings of the $19^{\text {th }}$ International Cartographic Conference and $11^{\text {th }}$ General Assembly of ICA, Ottawa, Canada, August 14-21, 1999; Volume 2, pp. 1291-1300.

76. Winter, S. Location similarity of regions. ISPRS J. Photogramm. Remote Sensing 2000, 55, 189-200.

77. Song, W.; Haithcoat, T.L. Development of comprehensive accuracy assessment indexes for building footprint extraction. IEEE Trans. Geosci. Remote Sens. 2005, 43, 402-404.

78. Zhan, Q.; Molenaar, M.; Tempfli, K.; Shi, W. Quality assessment for geo-spatial objects derived from remotely sensed data. Int. J. Remote Sens. 2005, 26, 2953-2974.

79. Helldén, U. A test of Landsat-2 imagery and digital data for thematic mapping, illustrated by an environmental study in northern Kenya; University of Lund: Lund, Sweden, 1980; Lunds Universitets Naturgeografiska Institution, Rapporter och Notiser 47.

80. Congalton, R.G.; Green, K. Assessing the Accuracy of Remotely Sensed Data: Principles and Practices; Lewis Publishers: Boca Raton, FL, USA, 1999.

81. Kareinen, J. Maastotietokannan ajantasaistus laserkeilausaineistosta (Updating NLS Topographic Database from laser scanner data); Master's thesis, Helsinki University of Technology: Espoo, Finland, 2008 (in Finnish, English abstract).

(C) 2010 by the authors; licensee MDPI, Basel, Switzerland. This article is an open-access article distributed under the terms and conditions of the Creative Commons Attribution license (http://creativecommons.org/licenses/by/3.0/). 